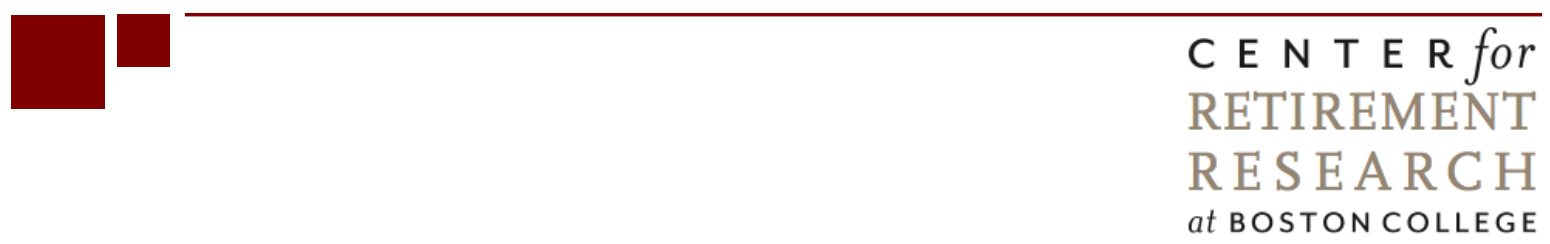

\title{
DOES ACCESS TO HEALTH INSURANCE INFLUENCE WORK EFFORT AMONG DISABILITY CASH BENEFIT RECIPIENTS?
}

\author{
Norma B. Coe and Kalman Rupp \\ CRR WP 2013-10 \\ Submitted: March 2013 \\ Released: April 2013
Center for Retirement Research at Boston College
Hovey House
140 Commonwealth Avenue \\ Chestnut Hill, MA 02467 \\ Tel: 617-552-1762 Fax: 617-552-0191 \\ http://crr.bc.edu
}

Norma B. Coe is an assistant professor at the University of Washington. Kalman Rupp is a senior economist in the Office of Research, Evaluation and Statistics at the U.S. Social Security Administration (SSA). The research reported herein was pursuant to a grant from the SSA, funded as part of the Retirement Research Consortium (RRC). The findings and conclusions expressed are solely those of the authors and do not represent the views of SSA, any agency of the federal government, the RRC, the University of Washington, or Boston College. The authors would like to thank Francoise Becker and Kendrew Wong for excellent programming assistance, and Paul Davies, Howard Iams, Susan Grad, Joyce Manchester, and Christopher Tamborini for helpful comments. All errors are their own.

(C) 2013, Norma B. Coe and Kalman Rupp. All rights reserved. Short sections of text, not to exceed two paragraphs, may be quoted without explicit permission provided that full credit, including (C) notice, is given to the source. 


\begin{abstract}
About the Center for Retirement Research
The Center for Retirement Research at Boston College, part of a consortium that includes parallel centers at the University of Michigan and the National Bureau of Economic Research, was established in 1998 through a grant from the Social Security Administration. The Center's mission is to produce first-class research and forge a strong link between the academic community and decision-makers in the public and private sectors around an issue of critical importance to the nation's future. To achieve this mission, the Center sponsors a wide variety of research projects, transmits new findings to a broad audience, trains new scholars, and broadens access to valuable data sources.
\end{abstract}

\author{
Center for Retirement Research at Boston College \\ Hovey House \\ 140 Commonwealth Avenue \\ Chestnut Hill, MA 02467 \\ phone: 617-552-1762 fax: 617-552-0191 \\ e-mail: crr@bc.edu \\ crr.bc.edu
}

Affiliated Institutions:

The Brookings Institution

Massachusetts Institute of Technology

Syracuse University

Urban Institute 


\begin{abstract}
There is considerable policy concern about "DI lock" - that tying public health insurance coverage to cash disability benefit receipt contributes to the low exit rates due to work. This concern led Congress to institute continued health insurance eligibility after disability beneficiaries leave the cash-benefit rolls for work-related reasons. However, unlike the long literature on "job lock," the importance of the DI lock hypothesis - either before or after these extensions - has remained unquantified.

This paper tests whether "perceived DI lock” remains among disability beneficiaries, and whether state health insurance policies help alleviate the problem and encourage work among beneficiaries. The analysis includes both DI and SSI beneficiaries and tests if there are differential patterns between the two programs. We exploit state variation in the access and cost of health insurance caused by regulation of the non-group market, the existence of Medicaid buy-in programs, and Medicaid generosity, as well as detailed disability and health insurance program interactions. While we find little evidence overall of persistent DI-lock, heterogeneity is very important in this context. Our estimates suggest that increasing health insurance access does increase the likelihood of positive earnings among a subset of disability beneficiaries. We find evidence of SSI lock among beneficiaries with some Medicaid expenditures and find that both non-group health insurance regulation and generous Medicaid eligibility help alleviate the problem. We find evidence of remaining DI lock among individuals who do not have access to supplemental health insurance outside of Medicare. Medicaid buy-in programs alleviate the remaining DI lock.
\end{abstract}




\section{Introduction}

There are two health insurance systems in the United States for working-age individuals: (1) employer-sponsored coverage for employed individuals and their families; and (2) public health insurance - both Medicaid and Medicare- - for individuals who are deemed unable to work. Tying health insurance to employment has well-known adverse side-effects, often referred to as “job lock” (Gruber 2000, Gruber and Madrian 2004). Research suggests that job lock decreases job turnover, decreases entrepreneurial activity, and influences retirement timing (Gruber and Madrian 1994, Madrian 1994, Buchmueller and Valletta 1996). Similar adverse side effects could apply to welfare recipients or the disabled population: tying health insurance coverage to receipt of cash benefits may exacerbate the already strong incentives to stay on the welfare/disability rolls. Evidence suggests that "welfare lock” is statistically significant, though relatively small in magnitude (Ellwood and Adams 1990, Yelowitz 1995). The importance of DI lock remains unquantified, despite the substantial value of public health insurance benefits to the disabled. Autor and Duggan (2006) estimate that the present discounted value of Medicare expenditure on the average age-50 disability insurance (DI) beneficiary is more than 1.6 times the present discounted value of the DI cash benefit itself.

While there has been very little research that estimates the size or importance of DI lock, Congress has extended public health insurance coverage under specific conditions for individuals leaving the SSI or DI rolls. ${ }^{1}$ There remains concern that few recipients may know about these program provisions and remain "DI locked" due to fear of losing health insurance (Livermore, Roche, and Prenovitz 2009).

In this paper, we examine the "DI lock hypothesis" - the idea that tying public health insurance coverage to the receipt of disability benefits reduces work effort and disability program exit rates. We consider both major Social Security Administration (SSA) disability programs (DI and SSI), as well as complex program interactions between these programs. To test for DI lock, we exploit state-level variation in the access and affordability of health care for disabled individuals in both the non-group and the Medicaid markets.

This paper continues as follows. Section 1 discusses in detail the relevant disability and health insurance programs, and the interactions between these programs. Section 2 describes the

\footnotetext{
${ }^{1}$ There is work showing that applications and participation in SSI and DI are sensitive to health insurance availability (i.e. Yelowitz 2000, Gruber and Kubik 2002), but we are unaware of work testing whether individuals exit and/or return to work.
} 
existing patterns between health insurance and DI/SSI receipt. Section 3 details the hypotheses being tested. Section 4 describes the models estimated, and Section 5 describes the unique administrative data used for this investigation. Section 6 provides descriptive statistics, and Section 7 describes the results. Section 8 concludes that health insurance access has an impact, albeit small, on the work effort among subgroups of the disabled.

\section{Disability Programs, Health Insurance and Employment Interactions}

Disability Programs. Much has been written about the rules and benefit structure of SSA's disability programs, so we provide only details that are most directly relevant to our study. ${ }^{2}$ DI is a social insurance program, while SSI is a means-tested program for the elderly and disabled individuals. The two programs share the same criteria to qualify as disabled, but they differ in their non-disability related eligibility criteria. DI benefit eligibility is contingent on “DI-insured status,” which requires a certain level of lifetime and recent work history. ${ }^{3}$ DI benefits are determined by a function of past earnings based on the same formula that determines Social Security retirement benefits. In May 2012, the average disabled worker benefit was $\$ 1,111$ per month.

SSI, in contrast, is a categorical negative income tax program with a strict resource test and an income test with a federal benefit ceiling, commonly referred to as the Federal Benefit Rate (FBR), set at \$698 per month for individuals and \$1,048 per month for couples in 2012. ${ }^{4}$ Federal SSI benefits are determined by subtracting "countable income” from the FBR. Countable income excludes the first \$20 of any income (earned or unearned) and an additional $\$ 65$ of earned income. Above these exclusions, benefits phase out at 50 cents for every dollar of earned income and dollar-for-dollar for unearned income. Differences and changes in unearned and earned income result in federal SSI benefits that can vary between zero and the FBR; the average monthly federal SSI benefit for beneficiaries aged 18-64 is \$533 in 2012.

\footnotetext{
${ }^{2}$ We look for DI lock among beneficiaries, so the most relevant rules are those pertaining to work effort. An excellent summary of the key features of the DI and SSI programs and work incentives is a paper by Newcomb, Payne and Waid (2003).

${ }^{3}$ In addition to the requirement of being fully insured for Social Security benefits, DI-insured status requires 20 quarters of coverage in the previous 10 years. This requirement is modified for people younger than age 31, but generally follows the pattern of requiring one quarter of coverage for each two calendar quarters that have elapsed since the age of 21. A quarter of coverage is currently defined as a specific amount of earnings and was equivalent to $\$ 1,130$ in 2012.

${ }^{4}$ Supplementary state benefits are also available in many states with the generosity of supplementary benefits considerably varying across state. We currently ignore this state variation in benefit levels.
} 
These programs have complex longitudinal interactions. Many DI beneficiaries also receive SSI benefits over time. Some eventual DI beneficiaries receive SSI benefits during the 5-month DI waiting period. After this initial waiting period, DI beneficiaries with relatively low benefits can remain on the SSI-rolls to "top-up" their income (Rupp and Riley 2011). DI beneficiaries with relatively high benefits cannot qualify for SSI, because the DI benefit is countable income in the SSI benefit formula; except for the \$20 disregard, SSI benefits are reduced dollar-for-dollar of monthly DI benefits (Rupp et al 2007). Importantly for this study, individuals who work their way off the DI rolls may become eligible for SSI benefits.

Health Insurance. Public health insurance is paired with SSA's cash disability programs. SSI beneficiaries are categorically eligible for Medicaid in most states and gain immediate access to the program. DI beneficiaries receive Medicare after a 24-month waiting period effectively 29 months since disability onset because it is additive with the 5-month DI waiting period. For those DI beneficiaries who are also SSI-eligible, Medicaid can cover them during the 5-month DI waiting period and potentially through the Medicare waiting period. DI-SSI concurrent beneficiaries become "dually eligible" for Medicare and Medicaid after the end of the Medicare waiting period (Rupp and Riley 2012). Medicare remains the primary payer for these dually eligible beneficiaries.

Beneficiaries may also be covered by private insurance. Employer-sponsored (group) insurance could be secured through their spouse's employer or via COBRA coverage if the individual was previously insured through their employer. ${ }^{5}$ Beneficiaries can also buy private insurance in the non-group market. States have a variety of underwriting regulations for the nongroup market that impact the price and access to non-group health insurance and that are especially relevant for disabled individuals. The two most common regulations - and the ones we focus on in this paper - are "guaranteed issue" and "community rating." Guaranteed issue means that insurers have to offer every applicant a policy, but there are no limitations on the price of the policy. Community rating legislation limits the ability of the insurer to use individual characteristics for underwriting insurance policies. These regulations greatly affect non-group market prices and access, with differential impacts based on individual health risk. Unregulated markets have lower premiums for healthy individuals and higher premiums for sick

\footnotetext{
${ }^{5}$ Individuals applying for disability benefits are eligible for extended COBRA coverage, up to 29 months.
} 
individuals. While the success of the regulations varies, the general consensus is that regulated markets expand access for the least healthy individuals - they are more likely to be covered in the non-group market and less likely to be uninsured under strict-regulation regimes (Buckmueller and DiNardo 2002, Herring and Pauly 2006, Belloff and Cantor 2008, LoSasso and Lurie 2009, LoSasso 2011).

Finally, individuals may be eligible for Medicaid even if they are ineligible for SSI. States have a lot of latitude in designing their Medicaid programs, both in terms of benefits and the eligible population. States use income thresholds ranging between 100 and 300 percent of poverty in determining Medicaid eligibility - likely relevant income ranges for individuals who are trying to work their way off the disability rolls. Further, states have been introducing Medicaid buy-in programs, where disabled individuals whose income or assets disqualify them from traditional Medicaid may buy into the program, paying an income-adjusted premium.

Exiting the Disability Rolls. DI beneficiaries can be suspended or terminated if there is evidence suggesting that their work capacity has improved. This could happen through "medical recovery” or by earnings that exceed the SGA under certain conditions. ${ }^{6}$ Our data suggest that approximately 1 percent of DI beneficiaries leave the rolls per year either due to work effort or medical recovery.

SSI benefits can be discontinued through "medical recovery,” as well as due to increases in assets, earned income or unearned income that make the individual no longer eligible under the SSI means test. Because benefits are phased out at 50 cents on the earned dollar, SSI beneficiaries without other sources of countable income can earn up to at least twice the FBR without losing all cash benefits, a substantially higher level than the SGA for individuals and especially for couples. Our data suggest that approximately 4 percent of the SSI beneficiaries leave the rolls per year due to these reasons.

Because of the work disincentives embedded in DI and SSI program design, the low exit rates and the very long average duration in both programs, assisting DI and SSI beneficiaries to return to work has been a longstanding policy goal and a major motivation for many policy interventions. Several work incentive programs have been added to the DI program over the

\footnotetext{
6 "Medical recovery" is determined through continuing disability reviews (CDRs), whose use has varied widely over time. CDRs affect exits from both SSI and DI programs in the same way.
} 
years (U.S. Social Security Administration 2012). ${ }^{7}$ The primary DI work incentive program relevant to this study is the trial work period (TWP) - nine months in which beneficiaries can work and earn as much as they want and still be considered disabled. After nine TWP months have been accumulated over a rolling period of 60 -months, DI benefits are discontinued. ${ }^{8}$ The primary SSI work incentives relevant to this study are the income disregards: $\$ 20$ of income from any source, an additional $\$ 65$ of earned income, and 50 percent of any additional earnings are disregarded in the SSI benefit formula. This means that SSI beneficiaries may collect prorated benefits if their earnings are above the SGA but below $(2 * \mathrm{FBR}+\$ 85)$. SSI eligibility will generally continue unless there is a medical improvement or a change resulting in asset or income ineligibility.

While a continuation of Medicare or Medicaid benefits after cash benefits end was not part of the original cash benefit program design, they were later added for both programs partly due to concerns that low exit rates may be partially attributable to beneficiaries' fear of losing health insurance coverage. Currently beneficiaries can continue Medicare eligibility for 93 months. ${ }^{9}$ Continued Medicaid eligibility is available for former SSI recipients as long as the individual continues to have a disabling condition, need Medicaid in order to work, be unable to afford equivalent medical coverage without assistance, and meets all non-disability requirements of SSI. ${ }^{10}$

\section{Observed Health Insurance and Work Patterns Among the Disabled}

Health Insurance. While the uninsured rate in the United States has hovered around 20 percent for much of the recent past, Rupp, Davies and Strand (2008) find that only 5.5 percent of the DI-insured-only, ${ }^{11}$ working-age population at risk of applying to the program had no health insurance. Almost two-thirds had health insurance in their own name, another one-third through someone else, and less than 1 percent relied on public health insurance under Medicaid or

\footnotetext{
${ }^{7}$ See Newcomb, Payne and Waid (2003) for a more complete discussion.

${ }^{8}$ Any month the beneficiary's monthly earnings surpass a certain threshold (in 2012 it is $\$ 720$ ) is regarded to be a TWP month. After the TWP is completed, beneficiaries enter the Extended Period of Eligibility (EPE), a period of 36 months when benefits could be reinstates if their earnings fall below the SGA.

${ }^{9}$ Continued Medicare coverage for former DI beneficiaries no longer eligible for cash benefits who nevertheless continued to meet the disability test was first introduced in 1984 for 36 months, and the benefit was increased subsequently in several steps.

${ }^{10}$ Continued Medicaid eligibility for those exiting SSI was first legislated in 1980, and was made permanent in 1986 under Section 1619(b) of the Social Security Act.

${ }^{11}$ The DI-insured who are potentially at risk of concurrent SSI coverage are excluded from this statistic.
} 
Medicare. DI entrants, of course, are not a random sample of the at-risk population. This is nicely illustrated by the longitudinal analysis of Livermore, Stapleton and Claypool (2010), tracking DI entrants from 25-36 months prior to and 25-36 months after program entry. Among eventual DI entrants, the majority had private insurance coverage 1-12 months prior to entry, but 23 percent had no health insurance, and about 10 percent relied on Medicaid or Medicare. They also find that most of the uninsured DI-entrants remain uninsured during the Medicare waiting period. For others, private health insurance access is available even 25-36 months after DI entry, almost one-third still had coverage through a family member, 16 percent retained employer coverage, and 11 percent had private insurance from some other source. So while Medicaid and Medicare coverage substantially increases and becomes dominant two years after DI entry, a substantial minority retain some form of private health insurance. ${ }^{12}$

Despite the 24-month Medicare waiting period, Gruber and Kubik (2002) find that insurance coverage is stable upon application to the DI program among individuals age 50-64, but the source of the insurance changes. Both spousal health insurance coverage and Medicaid prevalence increase, offsetting the drop in employer-sponsored health insurance. ${ }^{13}$ Gruber and Kubik's findings suggest that individuals without alternative private sources of health insurance are less likely to apply to DI in the first place.

While little work has been done on the relationship between employment, health insurance and exits from SSA's disability programs, Muller, Scott, and Bye (1996) provide some interesting evidence by exploring the pattern of work behavior and earnings among SSI recipients. Their data set included years both before and after the introduction of continued Medicaid coverage to SSI beneficiaries, with one of the intended effects being the elimination of “SSI lock” arising from discontinuing Medicaid eligibility upon the discontinuation of SSI benefits. While they did not directly estimate the impact of extending Medicaid eligibility, the authors did not find any major changes in either the probability of work or the level of earnings

\footnotetext{
${ }^{12}$ A caveat to be noted here is that the survey-based data used by Livermore, Stapleton, and Claypool substantially underestimates public health insurance three years after DI entry. Based on administrative records, Rupp and Riley (2012) shows practically 100\% Medicare coverage after the end of the Medicare waiting period among DI-entrants (including DI-only and concurrents), with a nontrivial subgroup continuing with dual Medicaid and Medicare coverage.

${ }^{13}$ According to Livermore, Stapleton and Claypool (2010), however, both own employer and spousal coverage drops between the third year before and the third year after DI entry. All studies cited here confirm the offsetting effect of public health insurance.
} 
associated with the implementation. The authors suggested that the true effect may be zero or very small.

Work Effort and Exits. Despite work incentive programs, numerous demonstration projects, and the Ticket to Work legislation, the overwhelming evidence is that back-end interventions have only limited potential to increase exits and earnings among beneficiaries or previous beneficiaries. ${ }^{14}$ Reasons for the lack of success include: (1) the SSA disability screen is designed to benefit people with substantial disabilities that are expected to persist or result in death, so one would not expect a high exit rate if the screening is effective; (2) the strong work disincentive features of the programs, especially DI, which places a 100 percent tax on benefits if earnings increase over the SGA after the TWP, and (3) the depreciation of human capital over time.

Rupp and Riley (2011) find that only 2.8 percent of awardees first entitled to DI benefits in 2000 were alive and off the rolls five years after their first-ever DI entry prior to their $65^{\text {th }}$ birthday. The corresponding statistic is 9.8 percent for entrants first entitled to SSI benefits, reflecting the SSI means test and possibly other differences in DI and SSI work incentives. O’Leary, Livermore, and Stapleton (2011) confirm the low prevalence of work and work-related suspensions and terminations from SSA's disability programs, but they also highlight that the incidence of work activity and exits from these programs using longitudinal studies is higher than statistics measured from a cross-section. Still, the overwhelming impression from these studies is that few beneficiaries have sufficiently high earnings to exit the disability programs on a sustained basis, with somewhat better outcomes for beneficiaries aged 40 or younger. Schimmel, Stapleton and Song (2011) provide evidence on "parking” among DI beneficiaries keeping earnings just below the SGA limit in order to retain DI cash benefits. The authors estimate that few - between 0.2 and 0.4 percent of DI beneficiaries - were parked below the SGA level in the typical month between 2002 through 2006. Further, they find that the $\$ 200$ increase in the SGA in 1999 (from $\$ 500$ to $\$ 700$ per month) did not change earnings, although it did result in a small reduction in months spent off of the rolls because of work.

\footnotetext{
${ }^{14}$ One important caveat relates to the perceived successes of interventions focusing on youth transitioning from childhood SSI to adulthood. This population is not the focus of this paper.
} 


\section{Hypotheses and Identification Strategy}

State policy plays a large role in determining the access and affordability of health insurance within the state, both through non-group health insurance regulation and through eligibility rules for Medicaid enrollment. However, there has been little work to date examining the relationship between health insurance access, work incentives, and work activity among working-age beneficiaries. There are five testable hypotheses in which we examine these relationships:

First, despite legislation providing extended public health insurance coverage for people exiting the disability rolls for work related reasons there may remain an overall positive relationship between health insurance access and work effort, indicating the existence of DI-lock.

Hypothesis 1. Beneficiaries in states with easier access to health insurance will be more likely to work than their peers in states where health insurance is more difficult to access.

While changes in health insurance access could impact all disabled beneficiaries, certain subgroups may be more sensitive to health insurance access than others. Some likely candidates are: (1) individuals with disabilities that require positive, but only moderately high medical expenditure and thus gain more from health insurance compared to individuals with no health insurance expenditures; and (2) beneficiaries without access to spousal health insurance coverage.

Hypothesis 2. Disability beneficiaries with moderate medical expenditures will be more likely to work in states with easier access to health insurance, compared to individuals with no medical expenditures. However, we hypothesize no effect of state policies on people with high expenditures presumed to be severely disabled. ${ }^{15}$

To date, there has been little research on whether there is a correlation between health insurance coverage or health expenditure patterns and work effort among disabled beneficiaries more analysis of this effect has been done in the welfare context. Both Ellwood and Adams (1990) and Moffit and Wolfe (1992) find that the probability of exiting welfare decreases substantially as the imputed value of Medicaid rises. Moffitt and Wolfe also show that the value

\footnotetext{
${ }^{15}$ We define mutually exclusive and exhaustive groups of medical expenditure (zero-moderate-high), based on the notion that very high expenditures may be associated with a level of case severity that makes them unresponsive to financial incentives.
} 
of maintaining Medicaid coverage has a significant negative impact on the labor force participation of single mothers. However, their identification strategy is vulnerable because the primary determinant of differences in the valuation of Medicaid benefits - namely differences in health status - is likely to have a strong independent effect on both labor supply and welfare participation. This criticism could also be launched in the disability benefit context. It is important to note, however, that in this paper we do not test whether zero-expenditure beneficiaries are more likely to leave the rolls than high- or moderate expenditure beneficiaries. We are instead using a difference-in-difference strategy that compares zero expenditure beneficiaries and moderate expenditure beneficiaries in easy-access and difficult-access states.

The job-lock literature has shown that individuals with access to health insurance coverage from other sources - such as a spouse's employer - do not exhibit the same decreased job turnover rates due to health insurance access. The administrative data indicate whether a DIbeneficiary with Medicare coverage has health insurance from a private source, making Medicare the secondary payer. This private coverage could be from any source - previous employment, current employment, individual coverage, or spousal coverage - and allows us to test for differential sensitivity based on health insurance access.

Hypothesis 3. Disability beneficiaries with Medicare as a secondary payer will be less responsive to better access arising from state health insurance access regulations.

Another source of identifying groups who might be more responsive to health insurance access comes from the interactions between the two disability programs. Program interactions result in very different policy regimes with different incentive structures, which depend on (1) individual work history, in terms of which program and the benefit level one qualifies for, and (2) the income and assets of the individual, and how these compare with the SSI income and resource limits (Rupp and Riley, 2012).

The starting point of our strategy for the next set of hypotheses is a comprehensive analysis of the interactions of the DI and SSI benefit formulas following Rupp et al. (2007) and Rupp, Davies, and Strand (2008). DI beneficiaries may lose their benefit because their earnings exceed the Substantial Gainful Activity threshold (SGA). However, some individuals may become eligible for SSI benefits should their DI benefits cease due to earnings; thus SSI 
dampens the work-disincentive in the DI program. ${ }^{16}$ The impact of the work disincentive effect of the SGA “cliff” on DI beneficiaries has little empirical support in the literature, and thus we test this effect first. ${ }^{17}$

Figure 1 illustrates a simple, stylized example of the work incentives for a single individual. ${ }^{18}$ In this scenario, the individuals have no countable income other than the DI benefit plus own earnings. In the "DI-only, high assets" case, the individual has enough assets such that he never meets the SSI means test. If he returns to work, after the completing the TWP, the SGA is the only relevant earnings threshold, above which he loses all DI benefits, and eventually Medicare benefits.

In the second case, "DI only, low assets," the individual has also completed the TWP and has identical work history as in the first case. However, the individual's assets are low enough that he qualifies for SSI benefits should his DI benefits cease. This is important when his earnings surpass the SGA limit and he loses DI cash benefits. At this point he gains SSI benefits to top up his total income. Effectively, the individual with low assets faces a smaller SGA cliff. In addition, this individual gains Medicaid access during the period while his earnings are above the SGA but below $2 * \mathrm{FBR}+\$ 85 .{ }^{19}$ One would expect the SGA cliff to be more salient among the DI recipients who would not qualify for SSI should their earnings be between the SGA and $2 * \mathrm{FBR}+\$ 85$. If health insurance access is a barrier to work effort among disabled individuals, the SGA cliff would be even more salient in states where health insurance was more difficult to access, i.e. the state has no Medicaid buy-in program or does not strictly regulate the non-group market. $^{20}$

\footnotetext{
${ }^{16}$ The event that triggers the SGA-cliff is called "SGA-suspension” during the Extended Period of Eligibility (EPE), a period of 36 months when benefits can be reinstated if his earnings fall below the SGA threshold. The beneficiary's earnings must be above the Substantial Gainful Activity level to lose DI benefits, but it must be below $2 *$ Federal Benefit Rate $\$ 85$ to gain SSI benefits. In 2012, this range was between $\$ 1,010$ and $\$ 1,481$ per month for individual beneficiaries.

${ }^{17}$ See, for example, Schimmel, Stapleton and Song (2011).

${ }^{18}$ For simplicity, we ignore state SSI supplements, which will only increase the incentive measured here, biasing our estimates downward.

${ }^{19}$ Note that this effect is contingent on marital status as defined by the SSI program, because a higher FBR applies to "couple" units than to "individual" units. As a result the maximum value of the SSI dampening effect is larger for beneficiaries in a couple SSI unit than for beneficiaries in an individual SSI unit. Using the 2012 program parameters, the maximum SSI dampening effect is $\$ 235$ for an individual beneficiary and $\$ 585$ for a beneficiary in a couple unit.

${ }^{20}$ Once earnings are above $2 * \mathrm{FBR}+\$ 85$, the two scenarios are identical since neither individual remains eligible for DI or SSI benefits.
} 
Hypothesis 4A. DI beneficiaries who could qualify for SSI will earn more during the Extended Period of Eligibility (EPE) than DI beneficiaries who would not, because SSI dampens the work-disincentive effect of the SGA cliff.

Hypothesis 4B. The differential impact of the SGA cliff on earnings between DI only and potential DI-to-SSI beneficiaries will be less important in states with easier access to health insurance in the non-group market. Thus, we expect a negative interaction effect between access to SSI during the EPE and easier access to health insurance in the state.

Program interactions also inform our final set of hypotheses. DI and SSI program interactions imply different sizes of the SGA cliff among beneficiaries who are eligible for both DI and SSI benefits. Beneficiaries with relatively high DI benefits will lose a greater proportion of their disability benefits should their earnings cause them to lose DI cash benefits. The size and presumably the behavioral effect of the SGA cliff may thus depend heavily on the level of DI benefits.

Figure 2 illustrates the financial incentives for those who are eligible for both SSI and DI at the same time from their first month of DI benefit eligibility (after the 5-month DI waiting period). In all 4 scenarios illustrated, the individual has the same benefit level when he does not work, but a different proportion of his benefits come from each disability program. In the first scenario, "DI only, low assets," this individual is just barely eligible for SSI benefits, receiving only $\$ 1$ in benefits while his earnings are zero, and he loses it as soon as he earns $\$ 2$. On the other extreme, the SSI-only case, the individual just misses qualifying for DI benefits. Instead, he gets SSI benefits and Medicaid coverage as long as he earns less than $2 * \mathrm{FBR}+\$ 85$ and never qualifies for Medicare. The interim scenarios illustrate that the financial incentives for an individual depend greatly on the relative level of DI benefits. The size - and presumably the importance - of the SGA cliff depends heavily on the level of DI benefits, since the SSI benefit will kick in providing individuals with a benefit floor between the SGA and $2 * \mathrm{FBR}+\$ 85$, as well as Medicaid coverage.

Hypothesis 5A. Among beneficiaries who are eligible for DI and SSI benefits, the size of the DI benefit will be positively associated with earnings and program exits during the EPE. 
Hypothesis 5B. Among beneficiaries who are eligible for DI and SSI benefits, the SGA cliff and the eventual loss of Medicare coverage will be less important in states with easier access to health insurance coverage, controlling for the ratio of DI to SSI benefits (the size of the SGA cliff).

Again, we are unaware of any research that tests the importance of the SGA cliff as a work disincentive - or the relationship to health insurance access - in this way. One related piece is Schimmel, Stapleton and Song (2011), who test the effects of the SGA cliff in a very different context. Their work looks for "parking below the SGA" among DI-beneficiaries who have exhausted the TWP. They find that a small fraction -0.2 to 0.4 percent - of these beneficiaries has earnings just below the SGA, and that the increase in the SGA has no impact on average earnings for this group.

\section{Model}

Hypotheses 1-3. To begin, we estimate whether health insurance regulation has an overall impact on work effort among DI and SSI recipients. This impact is measured using the following probit model:

$$
\text { Work }_{i t}=\beta_{0}+\beta_{1} \text { HI } \text { Market }_{s t}+\beta_{2} X_{i}+\beta_{3} Z_{i t}+S_{i t}+\gamma_{t}+\varepsilon_{i t}
$$

where Work $_{i t}$ is an indicator for whether an individual has positive earnings. HI Market st $_{\text {it }}$ a vector of state-level variables, indicating changes in regulation in the health insurance market, and $\beta_{1}$ measures the effect of health insurance reform on work effort. The different types of health insurance regulation are measured separately to the extent that there is variation in implementation dates. We follow Herring and Pauly (2006) and combine the presence of guaranteed issue and community rating regulation into one variable for "strict" regulation since

these regulations are highly correlated. Separate variables indicate the presence of the Medicaid buy-in program, and Medicaid generosity, measured as the ratio of the number of Medicaid eligible to the number in poverty in a state. $\mathrm{X}_{\mathrm{i}}$ is a vector of time-invariant individual characteristics, which include initial disability diagnosis (congenital, endocrine, infections and parasitic, injuries, intellectual disability, mental, neoplasms, circulatory, digestive, genitourinary, nervous, respiratory, musculoskeletal [omitted group], other), an indicator for the presence of a 
secondary diagnosis, and gender. We also include indicators for prior earnings to capture capacity and taste for work prior to disability onset. We use two variables here: (a) inflationadjusted average earnings 5 to 10 years prior to a beneficiary’s first-ever disability award; and (b) the number of years for the same period with earnings. The first measure is intended to proxy pre-disability earnings capacity, while the second is intended to measure the degree of predisability labor force attachment in a way that is independent of earnings capacity. $Z_{\text {it }}$ is a vector of time-varying individual characteristics, including age categories and indicators for how long one has been on the disability rolls. Also included are indicators for the beneficiary's historical disability program status: have received only DI benefits to date, have received only SSI benefits to date (omitted group), or have had both DI and SSI benefits at some point since first disability award.

We include information on the number of months the individual was covered by Medicare and Medicaid at time t and t-1, and an indicator for the individual being dual-eligible at time t. We also create two categorical variables to measure the level of Medicare and Medicaid expenditures at time t, respectively. The expenditure is defined as "zero" if the individual has no expenditure that year (omitted group), “moderate” if the individual has between $\$ 1-\$ 6,000$ expenditure, and a "high” expenditure if the data indicate more than $\$ 6,000$ of claims that year. ${ }^{21}$ Also included is an indicator for Medicare being the "primary payer” among Medicare-covered individuals, so we don’t accidentally label a zero or moderate Medicare expenditure person with unobserved non-Medicare expenditures as healthy. $S_{i t}$ is a vector of state of residence fixedeffects, $\gamma_{t}$ is a vector of year fixed-effects.

Hypotheses 2 and 3 are tested in the same manner, estimating equation (1), with the introduction of interaction terms to test for differential response by payer status or health insurance expenditure. The sample for Hypothesis 3 is limited to beneficiaries who have Medicare coverage during the entire calendar year.

Hypotheses 4a and 4b: SGA Cliff. To test the Hypotheses 4a and 4b, we limit the sample to DI beneficiaries who have already exceeded the TWP period. This is an admittedly selected

\footnotetext{
${ }^{21}$ The selection of these categories was the result of an analysis of empirical patterns of medical expenditure distributions and their relationship to relevant outcomes such as death, disability program exits, and earnings during the subsequent year, as well as benchmarking against national statistics of average medical expenditures among persons in their early fifties (mainly reflecting the average for nondisabled individuals).
} 
subsample that would be potentially most responsive to the health insurance incentives that we are testing. We identify the subgroup that would potentially be eligible for SSI should they lose DI benefits as a result of earning above the SGA and below $2 * \mathrm{FBR}+\$ 85$ by examining their SSIparticipation during the 5-month DI waiting period. This subgroup is defined as serial DI beneficiaries, which are DI beneficiaries who transitioned from SSI-only status during the 5month DI waiting period to DI-only afterwards. We assume that individuals who were eligible for SSI before DI enrollment could be eligible after they lose DI benefits because of high earnings, and those who did not qualify beforehand will not qualify after. This is an imperfect approximation since members of the serial subgroup have DI benefits high enough to disqualify them from SSI without regard to any other sources of income and assets, and therefore SSA has no reason to assess hypothetical SSI eligibility as long as they receive DI benefits.

Once we limit the sample, we examine the impact on earnings in specific areas of the earning distribution, namely between the SGA and $2 * \mathrm{FBR}+\$ 85$. In 2012, this range was between \$1,010 and \$1,476 for individual beneficiaries, which is an admittedly narrow range. Thus we run both a probit, for earning above the SGA, and a cumulative probit model of the following type:

$$
\text { Earn }_{i t}=\beta_{0}+\beta_{1} \text { HI } \text { Market }_{s t}+\beta_{2} X_{i}+\beta_{3} Z_{i t}+\beta_{4} \text { Serial }_{i}+S_{i t}+\gamma_{t}+\varepsilon_{i t}
$$

where Earn is defined as an annual categorical variable: no work; less than the (12*SGA), between $(12 * \mathrm{SGA})$ and $12 *(2 * \mathrm{FBR}+\$ 85)$, and over $12 *(2 * \mathrm{FBR}+\$ 85) .{ }^{22}$ The other variables are the same as in equation (1), with the addition of an indicator for being a serial DI beneficiary.

\footnotetext{
${ }^{22}$ In contrast to some related literature that sets a minimum \$ threshold (e.g. \$1,000) rather than greater than zero as the indicator of "any work," in our ordered probits here we distinguish non-positive earnings as a separate category, although we also use other thresholds like $\$ 1,000$ and $\$ 10,000$ that are roughly tied to relevant programmatic thresholds. Our reason for using essentially a "zero earnings" category arises from the observation that the vast majority of beneficiaries (76 percent in our sample) fall into this category, and using the distinction between zero and positive earnings is invariant to factors such as earnings capacity, while a specific threshold like $\$ 1,000$ may be equivalent to about 100 hours of work for a minimum wage worker, but would represent trivial hours for high earners. While it is true that some zero (and definitely negative) earnings recorded may represent measurement error, the fact is that using our zero earnings indicator for "any work" does a great job in screening in disabled beneficiaries with no labor force experience at all. The justification of using a set \$ positive threshold on the theory that it reduces the chances of low earnings more likely to reflect measurement error is problematic because it ignores the earnings capacity connection discussed above, as well as the likely strong correlation between earnings capacity and the magnitude of measurement error.
} 
To test Hypothesis 4b, we modify equation (2) to include interaction terms between the health insurance regulations and an indicator for serial DI beneficiary.

Hypotheses 5a and 5b: SGA Cliff and $2 * F B R+\$ 85$. To test Hypotheses $5 \mathrm{a}$ and $5 \mathrm{~b}$, we limit the sample to beneficiaries who maintain SSI benefits even after the DI cash benefits kicked in after the end of the 5-month waiting period. The relevant sample consists of individuals who have already completed their TWP and are potentially subject to the discontinuation of DI benefits if they continue to work. Since the work outcome of interest is how much they earn, we again estimate both a probit for earning above the SGA and an ordered probit model of the following form:

$$
\text { Earn }_{i t}=\beta_{0}+\beta_{1} H I \text { Market }_{s t}+\beta_{2} X_{i}+\beta_{3} Z_{i t}+\beta_{4}(D I-E(S S I))+S_{i t}+\gamma_{t}+\varepsilon_{i t}
$$

The variables are defined as above, with the addition of a variable that captures how much the beneficiary would lose if the beneficiary earns above the SGA level (DI-E(SSI)), where E(SSI) is the expected SSI benefit they would receive once they earn above the SGA. To test Hypothesis $5 b$, we modify equation (3) to include interaction terms between the health insurance regulations and difference between DI and the E(SSI).

\section{Data}

This project uses a combination of administrative datasets. First, we use an individuallevel data file that was developed under a collaborative project between the Centers for Medicare and Medicaid Services and the U.S. Social Security Administration and was the first effort to create a longitudinal file of DI and SSI beneficiaries combined with Medicaid and Medicare records at the individual level (Rupp and Riley 2011, 2012). Our main analytical file is a 10percent sample of individuals ages 18-64 receiving SSDI or SSI at some point between 1999 and 2006. The file contains information on DI and SSI awardee characteristics, DI and SSI benefit eligibility, benefit amounts, and date of death on a monthly basis, and annual earnings histories from a variety of SSA administrative record systems. ${ }^{23}$ The earnings data were adjusted to account for certain non-wage items believed to be associated with $\mathrm{W}-2$ reports from certain

\footnotetext{
${ }^{23}$ The earnings records are restricted use and were processed by authorized SSA personnel.
} 
EINs. ${ }^{24}$ Administrative data on Medicaid and Medicare - both coverage and expenditures - was merged to the dataset. Medicare and Medicaid coverage variables are available on a monthly basis, while the expenditure data reflect annual totals. ${ }^{25}$

Second, we merge into this micro dataset publicly available state-level data on health insurance regulatory changes (guarantee issue, community rating), ${ }^{26}$ Medicaid generosity measures, and Medicaid buy-in programs for the disabled. ${ }^{27}$ We also added to the dataset statelevel unemployment rates from the Current Population Survey.

Our initial sample consists of nearly 1.6 million individuals observed on a monthly basis. Because many of our variables are observed only on an annual basis - earnings, expenditure from Medicare and Medicaid - we first collapse the data and create an individual-year (unbalanced) panel dataset. Individuals had to be alive and between ages 18 to 64 on January 1 of each year for inclusion. ${ }^{28}$ While the final data set is annualized, some monthly information is retained, such as the number of months a beneficiary had Medicaid, Medicare, or was in trial work period status. However, earnings - our main outcome of interest - is available only on an annual basis, while many of the concepts described above are monthly in nature - i.e., if a beneficiary earns between the SGA and $2 * \mathrm{FBR}+\$ 85$. In order to address this, we annualize the monthly levels (multiply the SGA and FBR by 12), as has been done in previous work (Schimmel, Stapleton and Song 2011). This process will miss month-to-month variations in earnings and will introduce some measurement error into the measurement of our outcomes of interest. However, it will still pick-up sustained earnings necessary to exit the disability rolls due to work effort.

\footnotetext{
${ }^{24}$ The results are highly robust to the use of this adjustment, but we believe that the adjusted series gives a more accurate reflection of earnings for the sample used for this study.

${ }^{25}$ For more detail on the source data sets, see Rupp and Riley (2011, 2012).

${ }^{26}$ Data on state regulations of health insurance were compiled from The Henry J. Kaiser Family Foundation (2010a; 2010b), and Georgetown University Health Policy Institute (2004).

${ }^{27}$ These data were compiled from Kehn, Croake, and Schimmel (2010), Croake and Liu (2009), Gruman et. al (2008), Jensen (2004, 2006), Georgia Department of Community Health (https://www.gmwd.org/WebForms/StaticContent1.aspx), Delaware Health and Social Services (http://dhss.delaware.gov/dhss/dmma/), Commonwealth of Kentucky (http://manuals.chfs.ky.gov/dcbs_manuals/DFS/VOLIVA/OMVOLIVA.pdf).

${ }^{28}$ While we focus on disability cash benefit and public health insurance expenditure data for the 1999 to 2006 period, benefit history going back to 1994 and earnings records going back to 1978 were available. From the longitudinal earnings records we created variables reflecting earnings 6-10 years prior to the start of the individual's first benefit eligibility spell.
} 
Since we test the various hypotheses with different samples, some of them quite complex in construction, the following provides a brief description of the four samples used in the analysis:

- $\quad$ Full Sample. This is based on a random 10-percent sample of current or former DI and/or SSI disability beneficiaries in the 50 States and the District of Columbia during 2000-2006. This person-level source file was converted to a person-year level file which is the source of the Full Sample and the three subsamples used in some analyses. The person-year file was constructed to include current or former beneficiaries alive and aged 18-64 during the applicable reference year (2000-2006) for the given person-year observation. The full sample is based on 1,587,698 person records and consists of 8,093,007 person-year observations. The number of personlevel observations is slightly lower for the sample used for regression analyses due to missing values. The full sample is used to test Hypotheses 1 and 2.

- Medicare-covered Beneficiaries Sample. This sample is a subset of the Full Sample. It is limited to person-year observations on DI and/or SSI beneficiaries or former beneficiaries who were Medicare-covered during all 12 months of the 2000-2006 reference year. The Medicare-covered Beneficiaries Sample is based on 885,855 person-level records and contains 4,006,209 person-year observations. The number of person-level observations is slightly lower for the sample used for regression analyses due to missing values. The Medicare-covered Beneficiaries sample is used to test Hypothesis 3.

- DI-Serial Sample. This sample is a subset of the Full Sample. It is limited to personyear observations with a completed Trial Work Period and to records satisfying either of two conditions with respect to benefit history prior to the 2001-2006 reference year. The two conditions are (a) DI beneficiaries with a history of DI-only benefitreceipt between first-ever disability award - no history of SSI receipt; we classify person-year observations satisfying this condition as "DI-only"; and (b) DI-only with a history of first-ever SSI awardee transitioning to DI-only after the completion of the 5-month DI waiting period without any subsequent episode of SSI beneficiary status prior to the 2001-2006 reference year; we classify person-year observations satisfying this condition “Serial.” The DI-Serial sample is based on 10.537 person-level records 
and contains 18,705 person-year observations. The number of person-level observations is slightly lower for the sample used for regression analyses due to missing values. The DI-Serial sample is used to test Hypotheses 4a and 4b.

- SSI-DI Concurrent Sample. This sample is a subset of the Full Sample. It is limited to person-year observations with a completed Trial Work Period, and to records that satisfy the following conditions: (a) not included in the DI-Serial sample; and (b) have a history of at least one month of DI and at least one month of SSI beneficiary status prior to the 2001-2006 reference year. These observations are classified as concurrent in a broad longitudinal sense of involvement with both SSI and DI but the sample includes observations without "concurrent” DI and SSI benefit receipt for any month prior to the 2001-2006 reference year. The SSI-DI Concurrent sample is based on 4,168 person-level records and contains 7,353 person-year observations. The number of person-level observations is slightly lower for the sample used for regression analyses due to missing values. The SSI-DI Concurrent sample is used to test Hypotheses 5a and5b.

\section{Descriptive Statistics}

Table 1 presents the sample means of our four samples: Hypotheses 1-2 (Full Sample), Hypothesis 3 (Medicare-covered Beneficiaries), Hypotheses 4a and 4b (DI-Serial Sample), and Hypotheses 5a and 5b (SSI-DI Concurrent Sample). The unit of observation for sample means is the person-year.

The first fact that jumps out from this table is that the earnings activities of the four different samples vary dramatically. Twenty-two percent of the overall sample has positive earnings, and only 7 percent earn above the SGA; those percentages are even lower among the Medicare-insured population. When we limit the samples to beneficiaries who are potentially impacted by the DI and SSI interactions, 88-89 percent have positive earnings, and 41 to 49 percent earn above the SGA. About 15 to 16 percent of the samples live in states with strict health insurance; 50-59 percent live in states with Medicaid buy-in programs, and, on average, there are 1.54-1.58 Medicaid beneficiaries in the state for every one person in poverty (Medicaid generosity). 
Mental and musculoskeletal conditions are the most common diagnoses among disability beneficiaries in our samples. One-half to two-thirds of the samples have more than one diagnosis.

On average, individuals in the Full Sample had over five months of Medicaid coverage this year and last year, while they had around six months of Medicare coverage this year and last. By construction, the Medicare-covered Beneficiaries sample has 12 months of Medicare coverage during the current year, and not surprisingly over 11 months during the preceding year. Interestingly, the months of Medicaid coverage statistic does not change much when we limit the sample to the Medicare-covered Beneficiaries sample: on average they still had over four months of Medicaid coverage this and the previous year. We see major differences in medical insurance coverage between the DI-Serial and SSI-DI Concurrent samples. This is to be expected, however, since we are selecting our sub-samples based on disability program participation. Among beneficiaries who are only receiving DI benefits once they have surpassed the 5-month waiting period and completed the TWP (DI-Serial), Medicaid covered only around 1.5 months this year and last year, and only 12-14 percent had both Medicaid and Medicare coverage. When we examine those TWP completers who have a history of getting both SSI and DI but are not serials (DI-Concurrent), the corresponding statistics increases to 5.5-6 months of Medicaid coverage for the current and previous year, respectively, and almost 50 percent had both Medicaid and Medicare coverage during the reference year.

Eighteen percent of the Full Sample had coverage from both disability programs during the current calendar year, but not surprisingly there is substantial variation between the other three samples. Approximately half of our samples is female. Half of the Full Sample is between the ages of 35 and 55 and almost a quarter is between 55 and 61.

Variables related to program participation - both characteristics related to eligibility for the DI program and health insurance - are the other margin in which we see significant differences between the samples. Prior average annual earnings, measured 6-10 years before the disability application, also vary dramatically by sample. The Full Sample had prior average annual earnings of almost $\$ 9,000$; the DI-Serial Sample had prior average annual earnings of over $\$ 20,000$. This is as expected since a history of higher earnings translates to higher DI benefits, which makes one less likely to meet the means test for SSI benefits after completion of the 5-month DI waiting period. There are also sharp differences in duration. Almost half of the 
Full Sample and the Medicare-covered Beneficiaries Sample (44-46 percent) have been on the disability rolls for 10 years or more. In contrast, the other two samples (DI-Serial and SSI-DI Concurrent samples) that are limited to beneficiaries with relatively strong labor force attachment (TWP completers) consist of records almost exclusively with less than five years of duration (around 90 percent for both samples).

Since we are using state and year fixed-effects in our empirical specification, we need to have variation in health insurance policy within a state over time for our identification strategy to be valid. Figures 3, 4 and5 illustrate that we do have the necessary variation. Figure 3 suggests that there has been some variation, albeit limited, in strict regulation regimes. There are a few states that both introduce and repeal strict health insurance regulation of the non-group market. Our identification comes from changes in Massachusetts, Kentucky, New Hampshire and New Jersey. Figure 4 illustrates an increase in the number of states with Medicaid buy-in programs over the years, with 36 states introducing a program by 2006. Figure 5 shows that there have been substantial year-to-year changes in states Medicaid program generosity, as measured by the having a more than 20 percent change in the ratio of number of adults insured by Medicaid to the percent of the adult state population in poverty.

\section{Results}

Overall effect. The results estimating equation (1) are presented in Table $2{ }^{29}$ To see if there are different effects based on which disability program(s) one is enrolled in, we present the results for the full sample (column 1) and for each subsample: DI-only (column 2), SSI-only (column 3), and DI-SSI concurrent (column 4). Each cell contains the probit coefficient, standard error in parentheses, and marginal effect in brackets. The marginal effects of the interaction terms account for the nonlinearity of the model (Ai and Norton 2003).

The coefficients of particular interest are the health insurance regulations. For the most part, the state health insurance measures are not significant predictors of earning. Medicaid buyin programs have a positive, but small, effect on earning, increasing the likelihood of positive earnings by about 0.2-0.5 percentage points. Medicaid generosity seems to have different effects on different program participants: the likelihood of earning among DI-only beneficiaries is

\footnotetext{
${ }^{29}$ The full results of estimating equation (1) are presented in Appendix Table 1.
} 
lower, by 0.3 percentage points, in states with high Medicaid coverage, while SSI-only beneficiaries are more likely to have positive earnings by 0.5 percentage points.

Differential Response based on Health Insurance Utilization. One potential reason for the lack of substantial effects overall in Table 2 is that only certain individuals would be expected to be responsive to non-group health insurance or Medicaid program eligibility, and so the non-responders are making the average effect close to zero. To test this hypothesis, we modify equation (1) to include interaction terms with levels of health expenditure, testing Hypothesis 2, presented in Tables 3A and 3B. ${ }^{30}$ The outcome of interest in Table 3A is the presence of positive earnings, while Table 3B models exits from the disability rolls. In both tables the first column presents the direct effect of the variable of interest on the work outcome; columns 2-4 present the interaction terms between the variables of interest and the health insurance regulations - strict regulation of the non-group market, Medicaid buy-in program, and Medicaid generosity, respectively. The interaction terms are the coefficients of interest since this is essentially a triple-difference specification, comparing beneficiaries between states, over time, by medical spending levels. Again, we test for different effects depending on program enrollment by separating the sample as before: Panel A presents the results for the entire sample, Panel B for the DI-only sample, C for the SSI-only sample, and D for the sample of individuals who have received both DI and SSI during their benefit history.

In this specification, the level-effects are also of interest. We find that medical spending is negatively related to earnings or leaving the disability rolls. Beneficiaries with no medical expenditures have a 4-7 percentage point higher likelihood of positive earnings than those with moderate or high medical expenditures, respectively. Beneficiaries with no medical expenditures are also more likely to leave the rolls than their counter parts with medical spending, by 9-14 percentage points (Table 3B, Panel A, Column 1). These patterns are consistent with two stories: (1) beneficiaries with high medical expenditures are sicker and less able to work, and (2) beneficiaries with high medical expenditures are more sensitive to losing health insurance and are less likely to work out of fear of losing health insurance benefits.

\footnotetext{
${ }^{30}$ The coefficients, standard errors, and marginal effects of the variables of particular interest are presented only due to space limitations. Full results are available from authors upon request.
} 
Given the level effects, the interaction effects reported are triple-differences. Controlling for state, year, and medical expenditure levels, these interaction terms test whether there is a differential in propensity to work between beneficiaries with no versus moderate/high medical expenditures in states with easier access to health insurance, compared to no versus moderate/high medical expenditure beneficiaries in states with more difficult or expensive access.

Here we find significant effects of regulation in the non-group market on work effort. Beneficiaries with moderate medical expenditures are more likely to have positive earnings in states that make access to health insurance easier: 0.3 percentage points higher in strictly regulated states; 07 percentage points higher in states with Medicaid buy-in programs; and 1.7 percentage points higher in states with more generous Medicaid eligibility. The Medicaid buy-in effect on earning is even larger for individuals with high medical spending: a 1.6 percentage point higher likelihood of having positive earnings. Medicaid generosity is less effective for high-spending individuals, increasing the likelihood of positive earnings by 0.8 percentage points. Strict regulation seems to lower the probability of working for beneficiaries with high medical expenditure by 1.3 percentage points.

When we break the sample down by disability program participation patterns, we see that the positive relationship between moderate health expenditure and positive earnings (Table 3A) in strictly regulated non-group health insurance markets is driven by SSI-beneficiaries (Panel C). Further, the relationship between Medicaid buy-in programs is not solely driven by individuals in a specific program - all 3 groups show this sensitivity (Panels B-D). All panels indicate that beneficiaries with moderate or high medical expenditures are more likely to have positive earnings in states with Medicaid buy-in programs.

Table 3B presents the results for leaving the disability rolls. First and foremost, beneficiaries with moderate or high medical expenditures - either on Medicaid or Medicare - are much less likely to exit the rolls than no-expenditure beneficiaries (9-14 percentage points). This is evident in the overall effect (Column 1, Panel A of Table 3B), and while evident in all subgroups, the magnitude is driven by the SSI-only recipients in our sample (Panel C). Among the SSI-only (Panel C), beneficiaries with no medical expenditures are 17-33 percentage points more likely to leave the disability rolls than their moderate- and high-medical expenditure counterparts. 
We find evidence that overall, compared to beneficiaries with no medical expenditure, beneficiaries with moderate or high level medical expenditures are more likely to leave the rolls in states with strict non-group health insurance markets. These effects are primarily driven by SSI-only beneficiaries (Panel C). Interestingly, Medicaid buy-in programs are actually associated with lower exit rates for all but DI-SSI beneficiaries. Generous Medicaid programs in general seem to ease SSI-lock for beneficiaries with moderate (and sometimes high) medical expenditures but are associated with lower exit rates among DI-beneficiaries. This differential effect between the disability programs warrants further investigation.

\section{Differential Response based on Current Health Insurance Access. Tables 4A and 4B} present the results testing Hypothesis 3: whether individuals with Medicare as a secondary payer - having current private insurance coverage (which is primary by law) - are less sensitive to health insurance access through the non-group market compared to those with only public insurance (Medicare and, in some cases, also Medicaid) coverage. The sample is limited to individuals with Medicare coverage for the entire calendar year. The results in Tables 4A and $4 \mathrm{~B}$ are presented in the same manner as results in Tables 3A and 3B, with each column presenting the level and interaction effect within the same probit regression model and each panel presenting the results of different samples based on disability program participation. ${ }^{31}$

The level-effects in this regression are also of interest. Overall, we find that disability beneficiaries with private health insurance are more likely to have positive earnings ( 0.5 percentage points) but less likely to leave the disability rolls (by 3.5 percentage points). The difference between these two outcomes seems to be driven by sub-samples. For example, DISSI beneficiaries with private insurance coverage are more likely to work (Table 4A, Panel C), but DI-only beneficiaries with private insurance coverage are less likely to leave the disability rolls (Table 4B, Panel B). DI-SSI beneficiaries in states with strict health insurance regulation are less likely to have positive earnings, while DI-only beneficiaries in Medicaid buy-in states are more likely to have positive earnings and less likely to have positive earnings in states with generous Medicaid programs.

\footnotetext{
${ }^{31}$ We omit the SSI-only category of beneficiaries since it is a selected group of individuals who would have Medicare coverage without DI insurance, and thus is not very informative.
} 
Again we find some sensitivity among disability beneficiaries to health insurance access; however, the direction is not as predicted. In Panel B, we estimate that DI-only beneficiaries who have Medicare as a secondary payer (and, as a result, do have private insurance) have a lower likelihood of having positive earnings when they live in states with a Medicaid buy-in program. Interestingly, if we examine exiting the disability rolls, defined as no longer receiving cash benefits (although they may still be in the EPE), we find the opposite effect, as shown in Table 4B. Overall, disability beneficiaries with Medicare as secondary payer have a 0.4 percentage point higher likelihood of leaving the rolls when their state introduces Medicaid-buy in programs.

However, strict regulation does seem to ease DI-lock among both DI and DI-SSI Medicare-covered beneficiaries. The second column in Table 4A shows that beneficiaries in strictly regulated states are 1.1 percentage points more likely to have positive earnings, and while both sub-groups are responsive, DI-SSI beneficiaries are the most responsive at 6 percentage points. Strict regulation also seems to help DI-SSI beneficiaries leave the rolls, by 2.3 percentage points (Table 4B, Panel C). Medicaid program generosity continues to have differing effects on DI-only and DI-SSI beneficiaries: DI-only beneficiaries with private insurance coverage are 0.4 percentage points more likely to leave the DI program, while DI-SSI beneficiaries with private insurance coverage are 1.2 percentage points less likely to leave the rolls.

\section{Differential Response for those who could gain SSI and Medicaid while leaving DI.} Table 5 presents the results where we test the response to the size of the SGA cliff on work effort. These hypotheses test whether beneficiaries who could qualify for SSI (and thus Medicaid) while working their way off the DI-rolls are less sensitive to state policies regarding health insurance access. In Panel A, we estimate a probit model to see if the likelihood of earning above the SGA depends on the DI-SSI program interactions and/or state health insurance policies. In Panel B we present the cumulative probit results that estimate the effect on the distribution of annual earnings, defined by the policy-relevant earning parameters (0; 1-SGA; SGA-2*FBR+\$85; more).

The level-effects reported in Panel A suggest that state policy itself is not correlated with beneficiaries earning above the SGA limit. Interestingly, it also suggests that those who would 
likely qualify for SSI benefits should they earn above the SGA limit are just as likely to earn above the SGA limit as beneficiaries who would not likely quality for SSI benefits. However, we find suggestive evidence that serial SSI-DI beneficiaries are more likely to earn above the SGA but less than the point at which they would lose SSI benefits $(2 * \mathrm{FBR}+\$ 85)$ in states with strict health insurance regulation. This effect is suggestive of "parking" below the SSI threshold. This result is counter-intuitive. A priori, we expected serial SSI-DI benefits to be more likely to work above the SGA limit and that access to health insurance outside of the Medicaid program would be less important to them. There are a few potential explanations for these results. First, the sample selection is quite restrictive - we have gone from over 1.6 million individuals in our baseline sample to estimating effects among only 10,000 beneficiaries. The small sample size means we lose precision. The counter-intuitive results may also be related to the possibility that while the estimation sample is selective, it may not be selective enough. In particular, in contrast to serial beneficiaries, DI-only in the sample may consist of persons with assets that disqualify them from SSI eligibility even during the 5-month waiting period, and also might have systematically higher PIA and different in other ways that make the counterfactual comparison problematic.

These groups are insensitive to Medicaid buy-in programs and Medicaid generosity parameters.

Differential Response due to Loss of DI Coverage and size of SGA cliff. The last hypotheses we test - 5A and 5B - concern non-serial beneficiaries with a history of receiving both SSI and DI. Because SSI acts as a back-stop, beneficiaries with a lower DI benefit who earn above the SGA cliff may lose less income than those with a relatively higher benefit. The results are presented in Table 6, which is set up the same way as Table 5.

Panels A and B suggests - both in the level and the interaction effects with two exceptions - that the earnings of this subsample of beneficiaries are neither responsive to the size of the SGA cliff (as measured by the difference between DI benefits and SSI benefits) nor to state health insurance policy. The exceptions stem from the cumulative probit results (panel B), which suggest that overall the size of the cliff is negatively correlated with earning above the SGA and below the point of losing SSI benefits, and that generous Medicaid policies help counteract that effect. There could be many potential explanations: (1) beneficiaries may not 
understand the rules well enough to respond according to economic theory; (2) since many of these beneficiaries have both Medicare and Medicaid, if they leave the disability rolls due to work they may be more likely to know about the continued coverage from at least one of these programs; (3) these beneficiaries may be less sensitive to health insurance policy since they may feel they have many insurance options currently and do not worry about access to health insurance in the future; and (4) Type II error.

\section{Conclusions}

The DI lock hypothesis is a longstanding policy concern, but it is relatively unexamined empirically. While disability beneficiaries can maintain public health insurance if they exit the rolls due to work, there remains concern that beneficiaries are unaware of this fact, and “perceived DI lock” continues. This paper sheds light on this phenomenon, and tests whether state health insurance policy can help alleviate this problem.

Overall, there is little relationship between state health insurance access and beneficiaries working or leaving the disability rolls. This may reflect the success of previous reforms extending Medicaid and Medicare eligibility for people leaving the DI and/or SSI rolls for workrelated reasons. SSI beneficiaries appear to be the most responsive to health insurance access gained through Medicaid, either through a buy-in program or generous eligibility rules. However, we find some evidence of remaining DI lock even after the expansion of continued Medicaid and Medicare eligibility for some subgroups, highlighting the importance of heterogeneity. Our findings suggest that different state-level policies assist the disabled to leave the rolls in certain situations. We find that Medicaid buy-in programs ease DI-lock among beneficiaries with medical expenditures and among beneficiaries without access to private health insurance. Further, we find that strict health insurance regulation helps to ease SSI lock among those with moderate medical expenditures and eases DI lock among beneficiaries without access to private health insurance. Finally, we find suggestive evidence to support the hypothesis that potential SSI-eligibility dampens the work disincentive effects of the SGA cliff among DI beneficiaries, but more research is needed in this area to achieve more definitive conclusions. 


\section{References}

Ai, Chunrong \& Norton, Edward C., 2003. "Interaction Terms in Logit and Probit Models." Economics Letters, Elsevier, Vol. 80(1): 123-129, July.

American Academy of Pediatrics. 1993. Medicaid State Reports, FY1993. Elk Grove Village, IL. 1994-1998. Medicaid State Reports, FY1994-FY1998. Elk Grove Village, IL.

Autor, David and Mark Duggan. 2006. “The Growth in the Social Security Disability Rolls: A Fiscal Crisis Unfolding.” Journal of Economic Perspectives 20(3): 71-96.

Belloff, Dina and Joel Cantor. 2008. "Private Insurance Coverage: A Case Study of the Small Group Market in New Jersey.” Albany, NY: New York State Health Policy Research Center.

Blank, Rebecca M. 1989. “The Effect of Medical Need and Medicaid on AFDC Participation.” Journal of Human Resources 24(1): 54-87.

Bound, John. 1989. “The Health and Earnings of Rejected Disability Insurance Applicants.” American Economic Review 79(3): 482-503.

Buckmueller, Thomas C. and John DiNardo. 2002. "Did Community Rating Induce an Adverse Selection Death Spiral? Evidence from New York, Pennsylvania, and Connecticut.” American Economic Review 92(1): 280-294.

Buchmueller, Thomas C. and Robert G. Valletta. 1996. “The Effects of Employer-Provided Health Insurance on Worker Mobility.” Industrial and Labor Relations Review 49(3): 439-455.

Centers for Medicare \& Medicaid Services. 1999. MSIS State Summary FY1999 Medicaid Eligibles, Beneficiaries, and Payments. Baltimore, MD.

—. 2000-2008. MSIS State Summary FY2000-FY2008 Medicaid Eligibles, Beneficiaries, and Payments. Baltimore, MD.

Croake, Sarah and Su Liu. 2009. "A Government Performance and Results Act (GPRA) Report: The Status of the Medicaid Infrastucture Grants Program as of 12/31/08.” Princeton, NJ: Mathmatica Policy Research, Inc.

Commonwealth of Kentucky. "Operational Manual Volume IVA: Medicaid (MA) and State Supplementation.” Available at: http://manuals.chfs.ky.gov/dcbs_manuals/DFS/VOLIVA/OMVOLIVA.pdf.

Delaware Health and Social Services. “Division of Medicaid \& Medical Assistance.” Available at: http://dhss.delaware.gov/dhss/dmma/. 
Ellwood, David and Kathleen Adams. 1990. "Medicaid Mysteries: Transitional Benefits, Medicaid Coverage, and Welfare Exits.” Health Care Financing Review 1990 Annual Supplement: 119-131.

Georgia Department of Community Health. "What is Georgia Medicaid for Workers with Disabilities (GMWD) Medicaid?” Available at:

https://www.gmwd.org/WebForms/StaticContent1.aspx

Georgetown University Health Policy Institute. 2004. "Summary of Key Consumer Protections in Individual Health Insurance Markets. April, 2004.” Washington, D.C.

Gruber, Jonathan. 2000. "Health Insurance and the Labor Market.” In Handbook of Health Economics, Volume 1A, edited by Anthony J. Culyer and Joseph P. Newhouse, 645-706. Amsterdam, Netherlands: Elsevier B.V.

Gruber, Jonathan and Jeffrey Kubik. 2002. "Health Insurance Coverage and the Disability Insurance Application Decision.” Working Paper 9148. Cambridge, MA: National Bureau of Economic Research.

Gruber, Jonathan and Brigitte C. Madrian. 1994. "Health Insurance and Job Mobility: The Effects of Public Policy on Job-Lock.” Industrial and Labor Relations Review 48(1): 86102.

— 2004. "Health Insurance, Labor Supply and Job Mobility: A Critical Review of the Literature.” In Health Policy and the Uninsured, edited by Catherine McLaughlin, 97178. Washington, DC: Urban Institute Press.

Gruman, Cindy, Sarah Croake, Jody Schimmel, and Su Liu. 2008. "A Government Performance and Results Act (GPRA) Report: The Status of the Medicaid Infrastructure Grants Program as of 12/31/07.” Princeton, NJ: Mathmatica Policy Research, Inc.

Henry J. Kaiser Family Foundation. 2010a. "50 State Comparisons: Individual Market Rate Restrictions (Not Applicable to HIPPAA Eligible Individuals.” Accessed April 12, 2011. Available at: http://www.statehealthfacts.org/comparetable.jsp?ind=354\&cat=7.

— 2010b. "50 State Comparisons: Individual Market Guaranteed Issue (Not Applicable to HIPPAA Eligible Individuals.” Accessed April 12, 2011. Available at: http://www.statehealthfacts.org/comparetable.jsp?ind=353\&cat=7.

Herring, Bradley and Mark V. Pauly. 2006. "The Effect of State Community Rating Regulations on Premiums and Coverage in the Individual Health Insurance Market.” Working Paper 12504. Cambridge, MA: National Bureau of Economic Research.

Jensen, Allen. 2004. "Initial Development of Medicaid Buy-In Program and Related Comprehensive Employment Initiatives October 2002.” 
—. 2006. "Initial Development of Medicaid Buy-In Program and Related Comprehensive Employment Initiatives October 2004.”

Kehn, Matthew, Sarah Croake and Jody Schimmel. 2010. “A Government Performance and Results (GPRA) Report: The Status of the Medicaid Infrastructure Grants Program as of 12/31/09.” Princeton, NJ: Mathmatica Policy Research, Inc.

Liu, Su, Henry T. Ireys, and Craig Thorton. 2008. "Participants in the Medicaid Buy-In Program, 2000-2004: Characteristics, Earnings, and Medical Expenditures.” Journal of Disability Policy Studies 19(2): 95-102.

Liu, Su and David Stapleton. 2010. "How Many SSDI Beneficiaries Leave the Rolls for Work? More Than You Might Think.” Disability Policy Research Brief 10-01. Washington, DC: Center for Studying Disability Policy (Mathematica Policy Research, Inc.).

Livermore, Gina A., Allison Roche, and Sarah Prenovitz. 2009. Work Activity and Use of Employment Supports Under the Original Ticket to Work Regulations: SSI and DI Beneficiaries with Work-Related Goals and Expectations. Washington, DC: Center for Studying Disability Policy (Mathematica Policy Research, Inc.).

Livermore, Gina A., David C. Stapleton, and Henry Claypool. 2009. "Health Insurance and Health Care Access Before and After SSDI Entry.” Publication 1255. New York, NY: The Commonwealth Fund.

LoSasso, Anthony T. 2011. "Community Rating and Guarantee Issue in the Individual Health Insurance Market.” Expert Voices January. Washington, DC: NIHCM Foundation.

LoSasso, Anthony T. and Ithai Z. Lurie. 2009. “Community Rating and the Market for Private Non-Group Health Insurance.” Journal of Public Economics 93(1-2): 264-279.

Maestas, Nicole, Kathleen Mullen, and Alexander Strand. 2011. "Does Disability Insurance Receipt Discourage Work? Using Examiner Assignment to Estimate Causal Effects of SSDI Receipt.” Working Paper WR-853-2. Santa Monica, CA: RAND.

Madrian, Brigitte C. 1994. "Employment-Based Health Insurance and Job Mobility: Is There Evidence of Job Lock?” Quarterly Journal of Economics 109(1): 27-54.

Moffitt, Robert and Barbara L. Wolfe. 1992. "The Effect of the Medicaid Program on Welfare Participation and Labor Supply.” Review of Economics and Statistics 74(4): 615-626.

Montgomery, Edward and John C. Navin. 2000. "Cross-State Variation in Medicaid Program and Female Labor Supply.” Economic Inquiry 38(3): 402-418.

Muller, L. Scott, Charles G. Scott, and Barry V. Bye. 1996. “Labor-Force Participation and Earnings of SSI Disability Recipients: A Pooled Cross-Sectional Times Series Approach to the Behavior of Individuals.” Social Security Bulletin 59(1): 22-42. 
Newcomb, Chad, Suzanne Payne, and Mikki D. Waid. 2003. "What Do We Know About Disability Beneficiaries' Work and Use of Work Incentives Prior to Ticket? Background Information and Baseline Data.” In Paying for Results in Vocational Rehabilitation: Will Provider Incentives Work for Ticket to Work? edited by Kalman Rupp and Stephen H. Bell, 31-69. Washington, DC: Urban Institute Press.

O’Leary, Paul, Gina A. Livermore, and David C. Stapleton. 2011. "Employment of Individuals in the Social Security Disability Programs.” Social Security Bulletin 71(3): 1-10.

Parsons, Donald O. 1980. “The Decline in Male Labor Force Participation.” Journal of Political Economy 88(1): 117-134.

Rupp, Kalman, Paul S. Davies and Alexander Strand. 2008. "Disability Benefit Coverage and Program Interactions in the Working-Age Population.” Social Security Bulletin 68(1): 130.

Rupp, Kalman and Gerald F. Riley. 2011. "Longitudinal Patterns of Participation in the Social Security Disability Insurance and Supplemental Security Income Programs for People with Disabilities.” Social Security Bulletin 71(2): 25-51.

Rupp, Kalman and Gerald F. Riley. 2012. "Longitudinal Patterns of Medicaid and Medicare Coverage among Disability Cash Benefit Awardees.” Social Security Bulletin 72(3):1935.

Rupp, Kalman, Alexander Strand, Paul S. Davies, and James Sears. 2007. "Benefit Adequacy among Elderly Social Security Retired-Worker Beneficiaries and the SSI Federal Benefit Rate.” Social Security Bulletin 67(3): 29-52.

Schimmel, Jody, David C. Stapleton, and Jae G. Song. 2011. "How Common is 'Parking' among Social Security Disability Insurance Beneficiaries? Evidence from the 1999 Change in the Earnings Level of Substantial Gainful Activity.” Social Security Bulletin 71(4): 7792.

Stapleton, David and Su Liu. 2009. "Will Health Care Reform Increase the Employment of People with Disabilities?” Research Brief 09-04. Washington, DC: Center for Studying Disability Policy (Mathematica Policy Research, Inc.).

U.S. Social Security Administration. 2012. The Red Book - A Guide to Work Incentives. Baltimore, MD.

U.S. Department of Labor. 2010. Employee Benefits in the United States - March 2010. News Release USDL-10-1044. Washington, DC: Bureau of Labor Statistics.

Winkler, Anne E. 1991. “The Incentive Effects of Medicaid on Women's Labor Supply.” Journal of Human Resources 26(2): 308-337. 
Yelowitz, Aaron S. 1995. "The Medicaid Notch, Labor Supply and Welfare Participation: Evidence from Eligibility Expansions.” Quarterly Journal of Economics 110(4): 909940.

. 2000. "Using the Medicare Buy-In Program to Estimate the Effect of Medicaid on the SSI Participation.” Economic Inquiry 38(3): 419-441. 
Table 1. Descriptive Statistics

Full sample ${ }^{1}$ : $\quad$ Medicare-covered Hypotheses 1-2 beneficiaries sample ${ }^{2}$. Hypothesis 3
DI-serial sample ${ }^{3}: \quad$ SSI-DI concurrent sample ${ }^{4}$ :

Hypotheses $4 a-4 b \quad$ Hypotheses $5 a-5 b$

\begin{tabular}{|c|c|c|c|c|}
\hline \multicolumn{5}{|l|}{ Outcome variables } \\
\hline Positive earnings & 0.22 & 0.17 & 0.88 & 0.89 \\
\hline Earn $>$ SGA & 0.07 & 0.03 & 0.49 & 0.41 \\
\hline Not receiving disability cash benefits & 0.29 & 0.18 & 0.49 & 0.44 \\
\hline \multicolumn{5}{|l|}{ State health insurance policy } \\
\hline Strict regulation & 0.15 & 0.15 & 0.16 & 0.16 \\
\hline Medicaid buy-in program & 0.50 & 0.50 & 0.59 & 0.57 \\
\hline Medicaid generosity & 1.55 & 1.54 & 1.58 & 1.57 \\
\hline \multicolumn{5}{|l|}{ Disability diagnoses } \\
\hline Congenital & 0.00 & 0.00 & 0.00 & 0.00 \\
\hline Endocrine & 0.04 & 0.04 & 0.03 & 0.03 \\
\hline Infection or parasitic & 0.02 & 0.02 & 0.03 & 0.03 \\
\hline Injury & 0.03 & 0.04 & 0.06 & 0.04 \\
\hline Intellectual disability & 0.12 & 0.10 & 0.02 & 0.08 \\
\hline Mental & 0.28 & 0.27 & 0.27 & 0.44 \\
\hline Neoplasm & 0.02 & 0.02 & 0.08 & 0.03 \\
\hline Circulatory & 0.07 & 0.08 & 0.09 & 0.05 \\
\hline Digestive & 0.01 & 0.01 & 0.02 & 0.02 \\
\hline Genitourinary & 0.01 & 0.02 & 0.04 & 0.02 \\
\hline Muscular & 0.18 & 0.21 & 0.21 & 0.14 \\
\hline Nervous System & 0.08 & 0.09 & 0.10 & 0.08 \\
\hline Respiratory & 0.03 & 0.02 & 0.02 & 0.02 \\
\hline Other & 0.01 & 0.01 & 0.01 & 0.01 \\
\hline Unknown & 0.10 & 0.06 & 0.01 & 0.01 \\
\hline
\end{tabular}


Table 1. Descriptive Statistics (cont'd)

\begin{tabular}{|c|c|c|c|c|}
\hline & $\begin{array}{l}\text { Full sample }{ }^{1} \text { : } \\
\text { Hypotheses 1-2 }\end{array}$ & $\begin{array}{c}\text { Medicare-covered } \\
\text { beneficiaries sample }{ }^{2} \text { : } \\
\text { Hypothesis } 3\end{array}$ & $\begin{array}{l}\text { DI-serial sample }{ }^{3} \text { : } \\
\text { Hypotheses } 4 a-4 b\end{array}$ & $\begin{array}{c}\text { SSI-DI concurrent sample } \\
\text { Hypotheses } 5 a-5 b\end{array}$ \\
\hline Presence of secondary diagnosis indicator & 0.48 & 0.47 & 0.55 & 0.66 \\
\hline \multicolumn{5}{|l|}{ Health insurance and expenditures ${ }^{5}$} \\
\hline Months on Medicaid & 5.46 & 4.27 & 1.44 & 5.46 \\
\hline Months on Medicaid last year & 5.32 & 4.27 & 1.66 & 5.94 \\
\hline Moderate Medicaid expenditures & 0.30 & 0.29 & 0.15 & 0.47 \\
\hline Moderate Medicaid expenditures last year & 0.30 & 0.28 & 0.15 & 0.46 \\
\hline High Medicaid expenditures & 0.23 & 0.18 & 0.05 & 0.15 \\
\hline High Medicaid expenditures last year & 0.22 & 0.18 & 0.06 & 0.19 \\
\hline Months on Medicare & 6.29 & 12.00 & 9.16 & 9.80 \\
\hline Months on Medicare last year & 5.63 & 11.28 & 6.20 & 7.01 \\
\hline Moderate Medicare expenditures & 0.29 & 0.53 & 0.38 & 0.49 \\
\hline Moderate Medicare expenditures last year & 0.27 & 0.53 & 0.28 & 0.38 \\
\hline High Medicare expenditures & 0.13 & 0.26 & 0.13 & 0.16 \\
\hline High Medicare expenditures last year & 0.10 & 0.20 & 0.09 & 0.09 \\
\hline Both Medicaid and Medicare & 0.21 & 0.39 & 0.14 & 0.49 \\
\hline Both Medicare and Medicaid last year & 0.19 & 0.38 & 0.12 & 0.41 \\
\hline Medicare is secondary payer & 0.03 & 0.06 & 0.10 & 0.05 \\
\hline \multicolumn{5}{|l|}{ Demographics } \\
\hline Female & 0.49 & 0.46 & 0.48 & 0.50 \\
\hline Age 18-24 & 0.07 & 0.02 & 0.03 & 0.17 \\
\hline Age 25-29 & 0.05 & 0.03 & 0.05 & 0.16 \\
\hline Age 30-34 & 0.06 & 0.05 & 0.08 & 0.13 \\
\hline Age 35-39 & 0.09 & 0.08 & 0.11 & 0.13 \\
\hline Age 40-44 & 0.12 & 0.12 & 0.14 & 0.12 \\
\hline
\end{tabular}


Table 1. Descriptive Statistics (cont'd)

\begin{tabular}{|c|c|c|c|c|}
\hline & $\begin{array}{l}\text { Full sample }{ }^{1}: \\
\text { Hypotheses 1-2 }\end{array}$ & $\begin{array}{c}\text { Medicare-covered } \\
\text { beneficiaries sample }{ }^{2} \text { : } \\
\text { Hypothesis } 3\end{array}$ & $\begin{array}{l}\text { DI-serial sample }{ }^{3} \text { : } \\
\text { Hypotheses } 4 a-4 b\end{array}$ & $\begin{array}{l}\text { SSI-DI concurrent sample } \\
\text { Hypotheses } 5 a-5 b\end{array}$ \\
\hline Age 45-49 & 0.14 & 0.14 & 0.15 & 0.11 \\
\hline Age 50-54 & 0.15 & 0.16 & 0.15 & 0.08 \\
\hline Age 55-61 & 0.23 & 0.27 & 0.22 & 0.08 \\
\hline Age 62-64 & 0.09 & 0.12 & 0.07 & 0.02 \\
\hline \multicolumn{5}{|l|}{ Earnings history } \\
\hline $\begin{array}{l}\text { Number of years with zero earnings 6-10 } \\
\text { years prior to first-ever disability award }\end{array}$ & 1.43 & 0.80 & 0.75 & 1.78 \\
\hline $\begin{array}{l}\text { Average earnings 6-10 year prior to first- } \\
\text { ever disability award }\end{array}$ & $\$ 8,934.52$ & $\$ 12,219.87$ & $\$ 20,007.74$ & $\$ 7,627.53$ \\
\hline \multicolumn{5}{|l|}{ Disability program information $^{6}$} \\
\hline Both DI and SSI & 0.18 & 0.27 & 0.06 & 0.55 \\
\hline Only DI & 0.44 & 0.71 & 0.94 & 0.45 \\
\hline Only SSI & 0.38 & 0.02 & 0.00 & 0.00 \\
\hline \multicolumn{5}{|l|}{$\begin{array}{l}\text { Number of months since first-ever disability- } \\
\text { award }^{7}\end{array}$} \\
\hline 1-12 months & 0.07 & 0.00 & 0.11 & 0.06 \\
\hline 13-24 months & 0.07 & 0.01 & 0.28 & 0.20 \\
\hline 25-36 months & 0.06 & 0.09 & 0.23 & 0.23 \\
\hline 37-48 months & 0.06 & 0.08 & 0.18 & 0.23 \\
\hline 49-60 months & 0.05 & 0.07 & 0.11 & 0.16 \\
\hline 61-72 months & 0.05 & 0.07 & 0.06 & 0.08 \\
\hline 73-84 months & 0.05 & 0.06 & 0.02 & 0.04 \\
\hline 85-96 months & 0.05 & 0.06 & 0.00 & 0.00 \\
\hline 97-108 months & 0.05 & 0.05 & 0.00 & 0.00 \\
\hline $109-120$ months & 0.05 & 0.05 & 0.00 & 0.00 \\
\hline $121+$ months & 0.44 & 0.46 & 0.00 & 0.00 \\
\hline
\end{tabular}


Table 1. Descriptive Statistics (cont'd)

\begin{tabular}{|c|c|c|c|c|}
\hline Sample size & & & & \\
\hline Number of beneficiaries & $1,587,698$ & 885,855 & 10,537 & 4,168 \\
\hline Person-year observations & $8,093,007$ & $4,006,209$ & 18,705 & 7,353 \\
\hline
\end{tabular}

${ }^{1} 10$ percent sample of current or former DI and/or SSI disability beneficiaries aged 18-64 and alive during 2000-2006 reference year based on individual records from SSA and CMS administrative data systems.

${ }^{2}$ Subsample limited to DI and/or SSI beneficiaries or former beneficiaries who are Medicare covered during 2000-2006 reference year.

${ }^{3}$ Subsample limited to DI beneficiaries with a history of DI-only benefit-receipt between first-ever disability award and 2001-2006 reference year or a history of first-ever SSI awardee transitioning to DI-only after the completion of the 5-month DI waiting period without any subsequent episode of SSI beneficiary status prior to the 2001-2006 reference year.

${ }^{4}$ Subsample limited to beneficiaries not classified as "DI-Serial" with history of at least one month in DI and at least one month in SSI beneficiary status prior to the 2001-2006 reference year.

${ }^{5}$ Months on Medicaid or Medicaid variables refer to the reference person-year observation. "Last year" refers to year immediately prior to reference year. Expenditure data are limited to program expenditures by the Medicaid and/or Medicaid programs based on CMS administrative records. For both programs expenditures were classified as follows: (a) no expenditure during year; (b) "moderate" expenditure defines as \$1-\$6,000; (c) "high" expenditure defined as \$6,001 or over.

${ }^{6}$ Classification is based on DI-only or SSI-only benefit-receipt between first-ever disability award and the reference year with a residual category of beneficiaries with at least one month in DI, and at least one month in SSI benefit receipt status during the given time-period.

${ }^{7}$ Number of calendar months elapsing between first-ever disability award and January of the reference year. May include months in non-beneficiary status, and therefore can be interpreted as upper-bound estimate of duration of disability benefit receipt (DI and/or SSI) during given time period. 
Table 2. Direct Effect of State Health Insurance Policies on Positive Earnings among Disability Beneficiaries

\begin{tabular}{|c|c|c|c|c|c|}
\hline & & ALL $^{1}$ & DI-only ${ }^{2}$ & SSI-only $^{2}$ & Both DI and SSI ${ }^{2}$ \\
\hline \multicolumn{6}{|c|}{ State health insurance policy } \\
\hline \multirow{3}{*}{\multicolumn{2}{|c|}{ Strict regulation }} & -0.018 & -0.036 & -0.011 & -0.047 \\
\hline & & $(0.015)$ & $(0.024)$ & 0.024 & 0.039 \\
\hline & & {$[-0.003]$} & {$[-0.004]$} & {$[-0.002]$} & {$[-0.007]$} \\
\hline \multirow{3}{*}{\multicolumn{2}{|c|}{ Medicaid buy-in program }} & $0.026^{*}$ & $0.022^{*}$ & $0.028^{*}$ & 0.014 \\
\hline & & $(0.004)$ & $(0.006)$ & 0.006 & 0.009 \\
\hline & & {$[0.004]$} & {$[0.002]$} & {$[0.005]$} & {$[0.002]$} \\
\hline \multirow{3}{*}{\multicolumn{2}{|c|}{ Medicaid generosity }} & 0.001 & $-0.024^{*}$ & $0.031^{*}$ & 0.023 \\
\hline & & $(0.007)$ & $(0.011)$ & 0.012 & 0.017 \\
\hline & & {$[0.000]$} & {$[-0.003]$} & [ 0.005] & [ 0.004] \\
\hline$\overline{\mathrm{N}}$ & Person-year observations ${ }^{3}$ & $8,089,831$ & $3,567,362$ & $3,068,715$ & $1,453,754$ \\
\hline
\end{tabular}

Note: All regressions include all applicable covariates listed in Appendix Table 1, as well as state and year fixedeffects. The table presents the coefficients, standard errors (in parentheses), and marginal effects (in brackets) from a probit model. Coefficients estimated to be statistically significantly different from zero at the 0.95 level of confidence are indicated by "*". Note that standard error estimates assume single random sampling and therefore include some downward bias.

110 percent sample of current or former DI and/or SSI disability beneficiaries aged 18-64 and alive during 20002006 reference year based on individual records from SSA and CMS administrative data systems.

2 Classification is based on DI-only or SSI-only benefit-receipt between first-ever disability award and the reference year with a residual category of beneficiaries with at least one month in DI, and at least one month in SSI benefit receipt status during the given time-period.

${ }^{3}$ Person-year observations are slightly lower than those reported in Table 1 descriptive analysis as a result of missing values resulting in exclusion of person-year observations from the model estimating the equations. 
Table 3A. Heterogeneous Effects of State Health Insurance Policies on Positive Earnings among Disability Beneficiaries

\begin{tabular}{|c|c|c|c|c|}
\hline \multicolumn{5}{|c|}{ Hypothesis 2: Medical Expenditures } \\
\hline \multirow[b]{2}{*}{ Outcome: Positive earnings } & \multirow[b]{2}{*}{ Level effect } & \multirow{2}{*}{\multicolumn{2}{|c|}{$\begin{array}{c}* \text { Medicaid buy-in } \\
\text { program }\end{array}$}} & \multirow[b]{2}{*}{ *Medicaid generosity } \\
\hline & & & & \\
\hline \multicolumn{5}{|c|}{ Panel A: All beneficiaries ${ }^{1}$ ( $N=8,089,831$ Person-year observations) } \\
\hline \multicolumn{5}{|l|}{ State health insurance policy } \\
\hline \multirow[t]{3}{*}{ Strict regulation } & -0.0074 & & & \\
\hline & 0.0159 & & & \\
\hline & {$[-0.004]$} & & & \\
\hline \multirow[t]{3}{*}{ Medicaid buy-in program } & $-0.0262 *$ & & & \\
\hline & 0.00461 & & & \\
\hline & [ 0.003] & & & \\
\hline \multirow[t]{3}{*}{ Medicaid generosity } & $-0.0647 *$ & & & \\
\hline & 0.00839 & & & \\
\hline & {$[-0.001]$} & & & \\
\hline \multicolumn{5}{|l|}{ Medical expenditures $^{2}$} \\
\hline \multirow[t]{3}{*}{ Moderate spending $(\$ 1-\$ 6,000)$} & $-0.4986 *$ & $0.0230 *$ & $0.0487 *$ & $0.1252 *$ \\
\hline & 0.0105 & 0.00639 & 0.00503 & 0.00723 \\
\hline & [- 0.039] & {$[0.003]$} & {$[0.007]$} & {$[0.017]$} \\
\hline \multirow[t]{3}{*}{ Highspending $(\$ 6,001+)$} & $-0.6072 *$ & $-0.1249 *$ & $0.1226 *$ & $0.0657 *$ \\
\hline & 0.0113 & 0.00664 & 0.00532 & 0.0076 \\
\hline & [- 0.069] & {$[-0.013]$} & {$[0.016]$} & {$[0.008]$} \\
\hline \multicolumn{5}{|c|}{ Panel B: DI-only ${ }^{3}$ ( $\mathrm{N}=3,567,362$ Person-year observations) } \\
\hline \multicolumn{5}{|l|}{ State health insurance policy } \\
\hline \multirow[t]{3}{*}{ Strict regulation } & 0.0144 & & & \\
\hline & 0.0247 & & & \\
\hline & {$[-0.005]$} & & & \\
\hline \multirow[t]{3}{*}{ Medicaid buy-in program } & -0.0109 & & & \\
\hline & 0.0071 & & & \\
\hline & {$[0.002]$} & & & \\
\hline \multirow[t]{3}{*}{ Medicaid generosity } & -0.017 & & & \\
\hline & 0.0129 & & & \\
\hline & [- 0.002] & & & \\
\hline \multicolumn{5}{|l|}{ Medical expenditures $^{2}$} \\
\hline \multirow[t]{3}{*}{ Moderate spending $(\$ 1-\$ 6,000)$} & $-0.2224 *$ & $-0.0449 *$ & $0.0211 *$ & -0.00769 \\
\hline & 0.0163 & 0.00953 & 0.00767 & 0.0113 \\
\hline & {$[-0.024]$} & {$[-0.004]$} & [ 0.002] & {$[-0.000]$} \\
\hline \multirow[t]{3}{*}{ High spending $(\$ 6,001+)$} & $-0.3383 *$ & $-0.2102 *$ & $0.0992 *$ & -0.0133 \\
\hline & 0.018 & 0.0104 & 0.00767 & 0.0122 \\
\hline & {$[-0.037]$} & {$[-0.018]$} & {$[0.010]$} & {$[-0.000]$} \\
\hline
\end{tabular}


Table 3A. Heterogeneous Effects of State Health Insurance Policies on Positive Earnings among Disability Beneficiaries (cont’d)

\begin{tabular}{|c|c|c|c|c|}
\hline \multicolumn{5}{|c|}{ Hypothesis 2: Medical Expenditures } \\
\hline \multirow[b]{2}{*}{ Outcome: Positive earnings } & \multirow[b]{2}{*}{ Level effect } & \multicolumn{3}{|c|}{ *Medicaid buy-in } \\
\hline & & *Strict regulation & program & *Medicaid generosity \\
\hline \multicolumn{5}{|c|}{ Panel C: SSI-only beneficiaries ${ }^{3}$ ( $N=3,068,715$ person-year observations) } \\
\hline \multicolumn{5}{|l|}{ State health insurance policy } \\
\hline \multirow[t]{3}{*}{ Strict regulation } & -0.0271 & & & \\
\hline & 0.0249 & & & \\
\hline & [-0.003] & & & \\
\hline \multirow[t]{3}{*}{ Medicaid buy-in program } & $-0.0193 *$ & & & \\
\hline & 0.0071 & & & \\
\hline & {$[0.003]$} & & & \\
\hline \multirow[t]{3}{*}{ Medicaid generosity } & $-0.0817 *$ & & & \\
\hline & 0.0133 & & & \\
\hline & [ 0.003$]$ & & & \\
\hline \multicolumn{5}{|l|}{ Medical expenditures $^{2}$} \\
\hline \multirow[t]{3}{*}{ Moderate spending $(\$ 1-\$ 6,000)$} & $-0.5922 *$ & $0.0763 *$ & $0.0649 *$ & $0.2204 *$ \\
\hline & 0.0168 & 0.0102 & 0.00802 & 0.0113 \\
\hline & {$[-0.036]$} & {$[0.013]$} & {$[0.010]$} & {$[0.036]$} \\
\hline \multirow[t]{3}{*}{ High spending $(\$ 6,001+)$} & $-0.8451 *$ & $-0.1083 *$ & $0.0921 *$ & $0.1436 *$ \\
\hline & 0.0189 & 0.011 & 0.00869 & 0.0126 \\
\hline & {$[-0.104]$} & {$[-0.011]$} & {$[0.014]$} & [ 0.019] \\
\hline \multicolumn{5}{|c|}{ Panel D: DI-SSI beneficiaries ${ }^{3}(\mathrm{~N}=1,453,754$ persor } \\
\hline \multicolumn{5}{|l|}{ State health insurance policy } \\
\hline \multirow[t]{3}{*}{ Strict regulation } & $0.0992 *$ & & & \\
\hline & 0.0425 & & & \\
\hline & {$[-0.007]$} & & & \\
\hline \multirow[t]{3}{*}{ Medicaid buy-in program } & $-0.0802 *$ & & & \\
\hline & 0.0144 & & & \\
\hline & {$[0.002]$} & & & \\
\hline \multirow[t]{3}{*}{ Medicaid generosity } & 0.0414 & & & \\
\hline & 0.0238 & & & \\
\hline & [ 0.003] & & & \\
\hline \multicolumn{5}{|l|}{ Medical expenditures $^{2}$} \\
\hline \multirow[t]{3}{*}{ Moderate spending $(\$ 1-\$ 6,000)$} & $-0.4361 *$ & $-0.1436 *$ & $0.0729 *$ & 0.00678 \\
\hline & 0.0307 & 0.0208 & 0.0149 & 0.0214 \\
\hline & [- 0.061] & {$[-0.023]$} & [ 0.013] & {$[0.000]$} \\
\hline \multirow[t]{3}{*}{ High spending $(\$ 6,000+)$} & $-0.3703 *$ & $-0.2171 *$ & $0.1515 *$ & $-0.0552 *$ \\
\hline & 0.0303 & 0.0202 & 0.0146 & 0.0208 \\
\hline & {$[-0.072]$} & {$[-0.038]$} & [ 0.027 ] & {$[-0.009]$} \\
\hline \multicolumn{5}{|c|}{$\begin{array}{l}10 \text { percent sample of current or former DI and/or SSI disability beneficiaries aged 18-64 and alive during 2000-2006 reference year } \\
\text { based on individual records from SSA and CMS administrative data systems. 3,176 observations were dropped from the sample frame } \\
\text { due to missing value of Medicaid generosity in Hawaii in 2000. } \\
2 \text { Expenditure data are limited to program expenditures by the Medicaid and/or Medicaid programs based on CMS administrative } \\
\text { records. For both programs expenditures were classified as follows: (a) no expenditure during year; (b) "moderate" expenditure defines } \\
\text { as \$1-\$6,000; (c) "high" expenditure defined as } \$ 6,001 \text { or over. In all of the regressions "no expenditure" is the reference category. } \\
3 \text { Classification is based on DI-only or SSI-only benefit-receipt between first-ever disability award and the reference year with a residual } \\
\text { category of beneficiaries with at least one month in DI, and at least one month in SSI benefit receipt status during the given time-period. }\end{array}$} \\
\hline
\end{tabular}


Table 3B. Heterogeneous Effects of State Health Insurance Policies on Disability Exits among Disability Beneficiaries

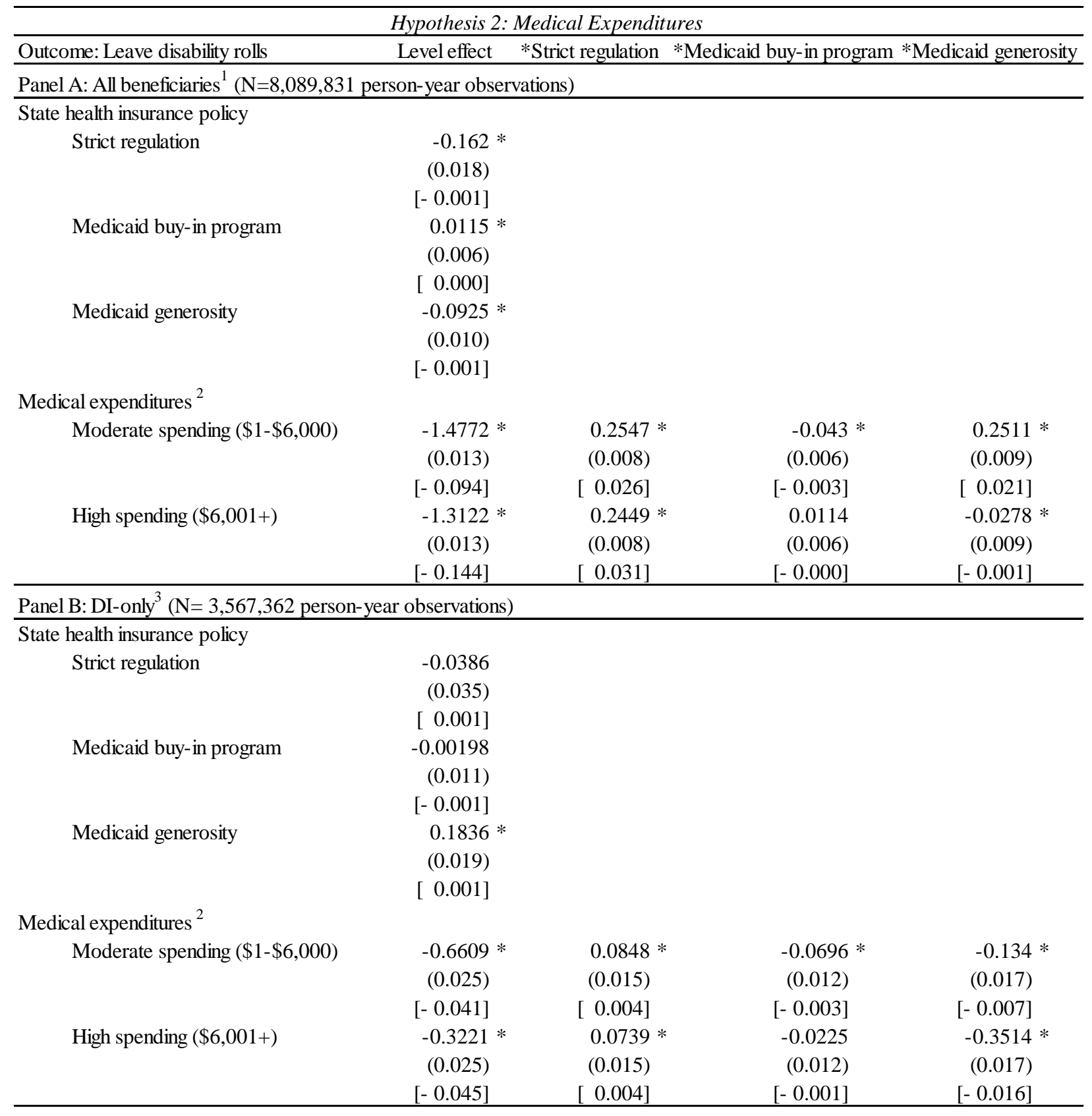


Table 3B. Heterogeneous Effects of State Health Insurance Policies on Disability Exits among Disability Beneficiaries (cont'd)

\begin{tabular}{|c|c|c|c|c|}
\hline \multicolumn{5}{|c|}{ Hypothesis 2: Medical Expenditures } \\
\hline Outcome: Leave disability rolls & Level effect & *Strict regulation & *Medicaid buy-in progral & *Medicaid generosity \\
\hline \multicolumn{5}{|c|}{ Panel C: SSI-only beneficiaries ${ }^{3}$ ( $N=3,068,715$ person-year observations) } \\
\hline \multicolumn{5}{|l|}{ 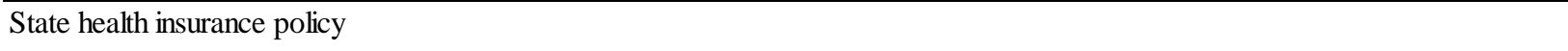 } \\
\hline Strict regulation & $\begin{array}{c}-0.1754 * \\
(0.028) \\
{[-0.003]}\end{array}$ & & & \\
\hline Medicaid buy-in program & $\begin{array}{c}0.0488 * \\
(0.009) \\
{[0.003]}\end{array}$ & & & \\
\hline Medicaid generosity & $\begin{array}{c}-0.0993 * \\
(0.016) \\
{[0.002]}\end{array}$ & & & \\
\hline \multicolumn{5}{|l|}{ Medical expenditures $^{2}$} \\
\hline \multirow[t]{2}{*}{ Moderate spending $(\$ 1-\$ 6,000)$} & $\begin{array}{c}-1.5733 * \\
(0.020)\end{array}$ & $\begin{array}{l}0.1941 * \\
(0.012)\end{array}$ & $\begin{array}{l}0.0159 \\
(0.010)\end{array}$ & $\begin{array}{l}0.2111 * \\
(0.014)\end{array}$ \\
\hline & {$[-0.165]$} & {$[0.030]$} & {$[0.001]$} & {$[0.027]$} \\
\hline \multirow[t]{2}{*}{ High spending $(\$ 6,001+)$} & $\begin{array}{l}-2.072 * \\
(0.022)\end{array}$ & $\begin{array}{l}0.2903 * \\
(0.013)\end{array}$ & $\begin{array}{c}-0.1329 * \\
(0.011)\end{array}$ & $\begin{array}{l}0.1074 \text { * } \\
(0.015)\end{array}$ \\
\hline & {$[-0.330]$} & {$[0.053]$} & {$[-0.021]$} & {$[0.010]$} \\
\hline \multicolumn{5}{|c|}{ 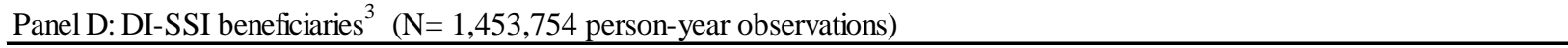 } \\
\hline \multicolumn{5}{|c|}{ State health insurance policy } \\
\hline Strict regulation & $\begin{array}{r}0.0883 \\
(0.057) \\
{\left[\begin{array}{l}0.002]\end{array}\right]}\end{array}$ & & & \\
\hline Medicaid buy-in program & $\begin{array}{c}-0.063 * \\
(0.018) \\
{[-0.000]}\end{array}$ & & & \\
\hline Medicaid generosity & $\begin{array}{r}-0.0574 \\
(0.030) \\
{\left[\begin{array}{l}0.001]\end{array}\right]}\end{array}$ & & & \\
\hline \multicolumn{5}{|l|}{ Medical expenditures $^{2}$} \\
\hline \multirow[t]{2}{*}{ Moderate spending $(\$ 1-\$ 6,000)$} & $\begin{array}{c}-1.8057 \text { * } \\
(0.039)\end{array}$ & $\begin{array}{c}-0.0886 * \\
(0.026)\end{array}$ & $\begin{array}{l}0.0384 * \\
(0.019)\end{array}$ & $\begin{array}{l}0.2493 \text { * } \\
(0.027)\end{array}$ \\
\hline & {$[-0.082]$} & [- 0.009] & {$[0.006]$} & {$[0.011]$} \\
\hline High spending $(\$ 6,001+)$ & $\begin{array}{c}-1.297 * \\
(0.038) \\
{[-0.117]}\end{array}$ & $\begin{array}{c}-0.0718 * \\
(0.025) \\
{[-0.012]}\end{array}$ & $\begin{array}{c}0.1245 \text { * } \\
(0.018) \\
{[0.012]}\end{array}$ & $\begin{array}{r}0.00902 \\
(0.026) \\
{[0.001]}\end{array}$ \\
\hline \multicolumn{5}{|c|}{$\begin{array}{l}\text { Note: All regressions include all applicable covariates listed in Appendix Table 1, as well as state and year fixed-effects. The table presents the } \\
\text { coefficients, standard errors (in parentheses), and marginal effects (in brackets) from a probit model. The table presents the coefficients, standard } \\
\text { errors (in parentheses), and marginal effects (in brackets) from a probit model. Coefficients estimated to be statistically significantly different } \\
\text { from zero at the } 0.95 \text { level of confidence are indicated by "*". Note that standard error estimates assume single random sampling and therefore } \\
\text { include some downward bias. } \\
110 \text { percent sample of current or former DI and/or SSI disability beneficiaries aged } 18-64 \text { and alive during } 2000-2006 \text { reference year based on } \\
\text { individual records from SSA and CMS administrative data systems. 3,176 observations were dropped from the sample frame due to missing value } \\
\text { of Medicaid generosity in Hawaii in } 2000 \text {. } \\
2 \text { Expenditure data are limited to program expenditures by the Medicaid and/or Medicaid programs based on CMS administrative records. For } \\
\text { both programs expenditures were classified as follows: (a) no expenditure during year; (b) "moderate" expenditure defines as } \$ 1-\$ 6,000 ; \text {; (c) } \\
\text { "high" expenditure defined as } \$ 6,001 \text { or over. In all of the regressions "no expenditure" is the reference category. } \\
3 \text { Classification is based on DI-only or SSI-only benefit-receipt between first-ever disability award and the reference year with a residual category } \\
\text { of beneficiaries with at least one month in DI, and at least one month in SSI benefit receipt status during the given time-period. }\end{array}$} \\
\hline
\end{tabular}


Table 4A. Heterogeneous Effects of State Health Insurance Policies on Positive Earnings among Disability Beneficiaries

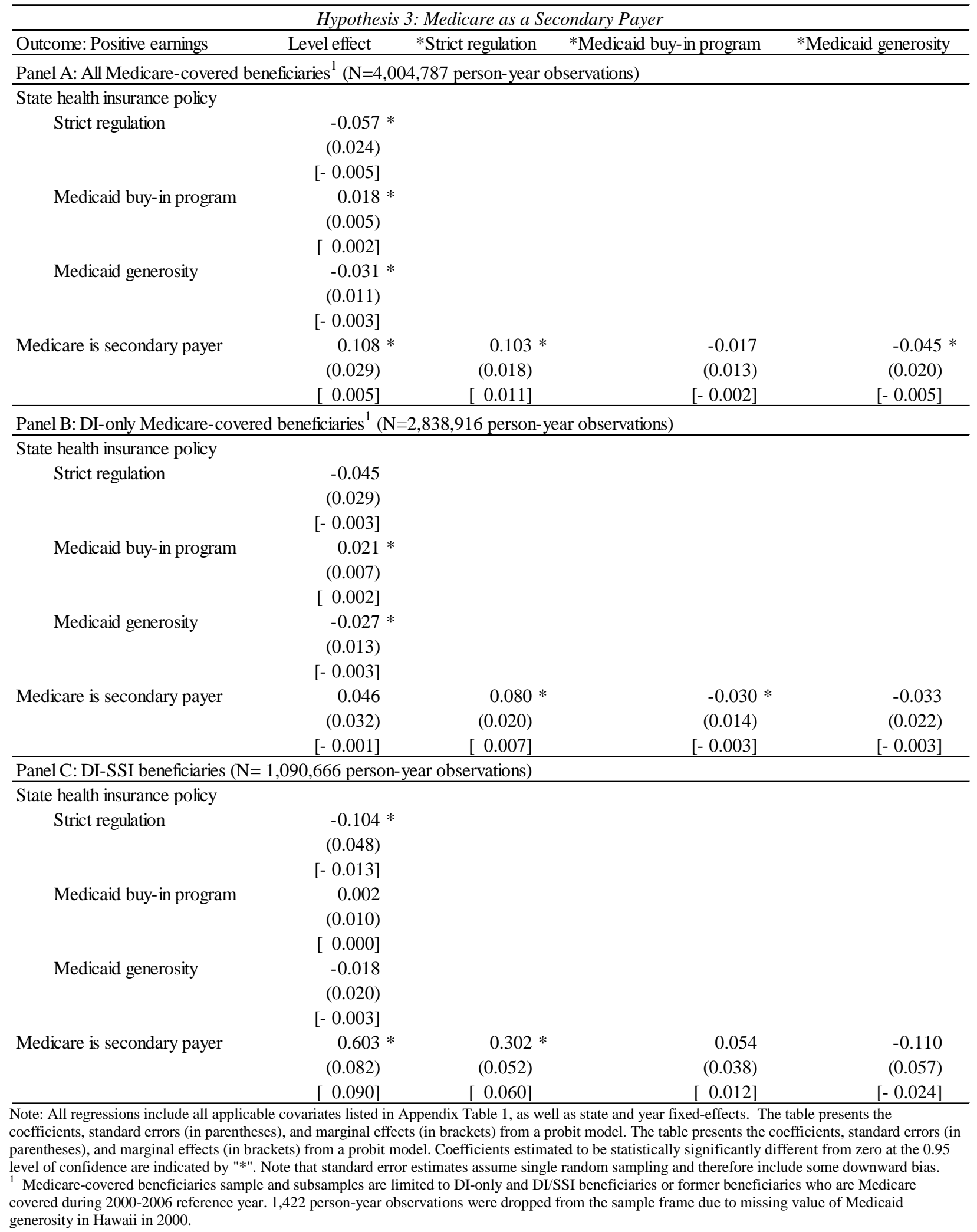


Table 4B. Heterogeneous Effects of State Health Insurance Policies on Disability Exits among Disability Beneficiaries

\begin{tabular}{|c|c|c|c|c|}
\hline \multicolumn{5}{|c|}{ Hypothesis 3: Medicare as a Secondary Payer } \\
\hline Outcome: Leave disability & Level effect & *Strict regulation & *Medicaid buy-in program & *Medicaid generosity \\
\hline \multicolumn{5}{|c|}{ Panel A: All Medicare-covered beneficiaries ${ }^{1}$ ( $\mathrm{N}=4,004,787$ person-year observations) } \\
\hline \multicolumn{5}{|l|}{ State health insurance policy } \\
\hline \multirow[t]{3}{*}{ Strict regulation } & -0.014 & & & \\
\hline & $(0.031)$ & & & \\
\hline & [- 0.001] & & & \\
\hline \multirow[t]{3}{*}{ Medicaid buy-in program } & -0.008 & & & \\
\hline & $(0.007)$ & & & \\
\hline & [- 0.000] & & & \\
\hline \multirow[t]{3}{*}{ Medicaid generosity } & 0.002 & & & \\
\hline & $(0.014)$ & & & \\
\hline & {$[0.000]$} & & & \\
\hline \multirow[t]{3}{*}{ Medicare is secondary payer } & $-0.824 *$ & 0.010 & $0.120 *$ & 0.010 \\
\hline & $(0.055)$ & $(0.034)$ & $(0.025)$ & $(0.038)$ \\
\hline & {$[-0.035]$} & [ 0.001$]$ & [ 0.004$]$ & [ 0.000$]$ \\
\hline \multicolumn{5}{|c|}{ Panel B: DI-only Medicare-covered beneficiaries ${ }^{1}$ ( $\mathrm{N}=2,838,916$ person-year observations) } \\
\hline \multicolumn{5}{|l|}{ State health insurance policy } \\
\hline \multirow[t]{3}{*}{ Strict regulation } & -0.019 & & & \\
\hline & $(0.038)$ & & & \\
\hline & [- 0.001] & & & \\
\hline \multirow[t]{3}{*}{ Medicaid buy-in program } & $-0.040 *$ & & & \\
\hline & $(0.009)$ & & & \\
\hline & {$[-0.002]$} & & & \\
\hline \multirow[t]{3}{*}{ Medicaid generosity } & 0.034 & & & \\
\hline & $(0.018)$ & & & \\
\hline & {$[0.002]$} & & & \\
\hline \multirow[t]{3}{*}{ Medicare is secondary payer } & $-1.116 *$ & 0.036 & $0.072 *$ & $0.139 *$ \\
\hline & $(0.067)$ & $(0.041)$ & $(0.030)$ & $(0.046)$ \\
\hline & [- 0.035] & {$[0.001]$} & {$[0.003]$} & [ 0.004] \\
\hline
\end{tabular}

State health insurance policy

Strict regulation $\quad 0.015$

$(0.067)$

[ 0.001$]$

Medicaid buy-in program $\quad-0.002$

$(0.014)$

[ 0.000$]$

Medicaid generosity $\quad 0.016$

$(0.028)$

[ 0.001$]$

Medicare is secondary payer $\quad-0.005$

0.364 *

$0.402 *$

-0.236 *

[- 0.002]

(0.076)

(0.063)

$(0.090)$

[ 0.023]

[ 0.026]

[- 0.012]

Note: All regressions include all applicable covariarates listed in Appendix Table 1, as well as state and year fixed-effects. The table presents the coefficients, standard errors (in parentheses), and marginal effects (in brackets) from a probit model. Coefficients statistically significantly different from zero at the 0.95 level of confidence are indicated by "*". Note that standard error estimates assume single random sampling and therefore include some downward bias.

${ }^{1}$ Medicare-covered beneficiaries sample and subsamples are limited to DI-only and DI/SSI beneficiaries or former beneficiaries who are Medicare covered during 2000-2006 reference year. 1,422 person-year observations were dropped from the sample frame due to missing value of Medicaid generosity in Hawaii in 2000. 
Table 5. Effect of SGA-Cliff and State Health Insurance Policies on Earnings among DI-only and DI-Serial Beneficiaries

\begin{tabular}{|c|c|c|c|c|}
\hline \multicolumn{5}{|c|}{ Hypothesis 4} \\
\hline & Level effect & *Strict regulation & *Medicaid buy-in program & *Medicaid generosity \\
\hline \multicolumn{5}{|c|}{ Panel A: Earn more than SGA, probit results $\left(\mathrm{N}=18,705\right.$ person-year observations) ${ }^{1}$} \\
\hline \multicolumn{5}{|l|}{ State health insurance policy } \\
\hline \multirow[t]{3}{*}{ Strict regulation } & -0.115 & & & \\
\hline & $(0.393)$ & & & \\
\hline & {$[-0.022]$} & & & \\
\hline \multirow[t]{3}{*}{ Medicaid buy-in program } & 0.051 & & & \\
\hline & $(0.070)$ & & & \\
\hline & {$[0.017]$} & & & \\
\hline \multirow[t]{3}{*}{ Medicaid generosity } & 0.014 & & & \\
\hline & $(0.142)$ & & & \\
\hline & {$[0.006]$} & & & \\
\hline \multirow[t]{3}{*}{ Serial SSI-DI beneficiary ${ }^{3}$} & -0.116 & $0.347 *$ & 0.050 & 0.041 \\
\hline & $(0.259)$ & $(0.163)$ & $(0.112)$ & $(0.183)$ \\
\hline & {$[-0.010]$} & [ 0.104$]$ & [ 0.015] & {$[0.012]$} \\
\hline \multicolumn{5}{|c|}{ Panel B: Earn more than SGA, but less than $2 * \mathrm{FBR}+\$ 85$, cumulative probit results $\left(\mathrm{N}=18,705\right.$ person-year observations) ${ }^{2}$} \\
\hline \multicolumn{5}{|l|}{ State health insurance policy } \\
\hline \multirow[t]{2}{*}{ Strict regulation } & -0.287 & & & \\
\hline & $(0.345)$ & & & \\
\hline \multirow[t]{2}{*}{ Medicaid buy-in program } & 0.047 & & & \\
\hline & $(0.061)$ & & & \\
\hline \multirow[t]{2}{*}{ Medicaid generosity } & -0.059 & & & \\
\hline & $(0.124)$ & & & \\
\hline \multirow[t]{2}{*}{ Serial SSI-DI beneficiary ${ }^{3}$} & 0.022 & $0.303 *$ & 0.102 & -0.072 \\
\hline & $(0.226)$ & $(0.143)$ & $(0.097)$ & $(0.159)$ \\
\hline
\end{tabular}

Note: All regressions include all applicable covariates listed in Appendix Table 1, as well as state and year fixedeffects. Panel A presents the coefficients, standard errors (in parentheses), and marginal effects (in brackets) from a probit model; Panel B presents the coefficients and standard errors (parentheses) from a cumulative probit model. Coefficients estimated to be statistically significantly different from zero at the 0.95 level of confidence are indicated by "*". Note that standard error estimates assume single random sampling and therefore reflect some downward bias.

${ }^{1}$ Estimates are based on DI-Serial Sample. The sample includes only individuals who first entered disability benefit status between 1999 and 2002. Person-year observations without a completed TWP are excluded. In addition, sample limited to individuals with a history of DI-only benefit-receipt during the 72 month period following first disability benefit award or individuals displaying a history of first-ever SSI awardee transitioning to DI-only after the completion of the 5-month DI waiting period without any subsequent episode of SSI beneficiary status over the same 72-month time-frame. The dependent variable in the probit equation equals 1 if earnings are greater than the SGA threshold applicable to the given year, otherwise the value is zero.

${ }^{2}$ Estimates are based on the DI-Serial Sample. The sample includes only individuals who first entered disability benefit status between 1999 and 2002. Person-year observations without a completed TWP are excluded. In addition, sample is limited to individuals with a history of DI-only benefit-receipt during the 72 month period following first disability benefit award or individuals displaying a history of first-ever SSI awardee transitioning to DI-only after the completion of the 5-month DI waiting period without any subsequent episode of SSI beneficiary status over the same 72-month time-frame. The dependent variable in the cumulative probit takes on the following values: (1) zero; (2) greater than zero and less than SGE; (3) SGA to less than $2 * F B R+\$ 65$; (4) $2 * F B R+\$ 65$ or above.

${ }^{3}$ Reference group: DI-only. 
Table 6. Effect of SGA-Cliff, 2*FBR Limit, and State Health Insurance Policies on Earnings among SSI-DI Concurrent (Nonserial) Beneficiaries

\begin{tabular}{|c|c|c|c|c|}
\hline \multicolumn{5}{|c|}{ Hypothesis 5} \\
\hline & Level effect & \multicolumn{3}{|c|}{ *Strict regulation *Medicaid buy-in program *Medicaid generosity } \\
\hline \multicolumn{5}{|c|}{ Panel A: Earn over SGA, probit results ( $N=7,346$ person-year observations) ${ }^{1}$} \\
\hline \multicolumn{5}{|l|}{ State health insurance policy } \\
\hline \multirow[t]{3}{*}{ Strict regulation } & 0.167 & & & \\
\hline & $(0.775)$ & & & \\
\hline & [ 0.121] & & & \\
\hline \multirow[t]{3}{*}{ Medicaid buy-in program } & 0.193 & & & \\
\hline & $(0.146)$ & & & \\
\hline & [ 0.018] & & & \\
\hline \multirow[t]{3}{*}{ Medicaid generosity } & 0.038 & & & \\
\hline & $(0.263)$ & & & \\
\hline & [ 0.029] & & & \\
\hline \multirow[t]{3}{*}{ Annual potential DI - potential SSI (in $\$ 1,000$ ) } & -0.019 & 0.034 & -0.019 & 0.009 \\
\hline & $(0.029)$ & $(0.017)$ & $(0.013)$ & $(0.019)$ \\
\hline & [-0.003] & [ 0.010$]$ & {$[-0.006]$} & [ 0.003] \\
\hline \multicolumn{5}{|c|}{ 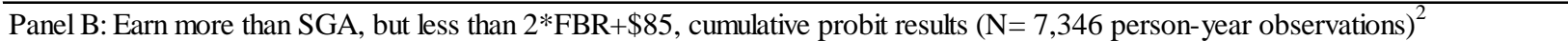 } \\
\hline \multicolumn{5}{|l|}{ State health insurance policy } \\
\hline Strict regulation & $\begin{array}{c}-0.557 \\
(0.697)\end{array}$ & & & \\
\hline \multirow[t]{2}{*}{ Medicaid buy-in program } & 0.133 & & & \\
\hline & $(0.124)$ & & & \\
\hline \multirow[t]{2}{*}{ Medicaid generosity } & -0.037 & & & \\
\hline & $(0.224)$ & & & \\
\hline \multirow[t]{2}{*}{ Annual potential DI - potential SSI (in $\$ 1,000$ ) } & $-0.051 *$ & 0.022 & -0.011 & $0.029 *$ \\
\hline & $(0.024)$ & $(0.015)$ & $(0.011)$ & $(0.016)$ \\
\hline
\end{tabular}

Note: All regressions include all applicable covariates listed in Appendix Table 1, as well as state and year fixedeffects. Panel A presents the coefficients, standard errors (in parentheses), and marginal effects (in brackets) from a probit model; Panel B presents the coefficients and standard errors (parentheses) from a cumulative probit model. Coefficients estimated to be statistically significantly different from zero at the 0.95 level of confidence are indicated by "*". Note that standard error estimates assume single random sampling and therefore reflect some downward bias.

${ }^{1}$ Subsample is limited to individuals not classified as "DI-Serial" who first entered disability benefit status between 1999 and 2002. In addition the individual has to satisfy the following requirement with respect to benefit history over the 72 months following first entry: have a history of at least two months of simultaneous DI and SSI beneficiary status during the 72-month time frame. 7 person-year observations were dropped due to missing values. The dependent variable in the probit equation equals 1 if earnings are greater than the SGA threshold applicable to the given year, otherwise the value is zero.

2 Subsample is limited to individuals not classified as "DI-Serial" who first entered disability benefit status between 1999 and 2002. In addition the individual has to satisfy the following requirement with respect to benefit history over the 72 months following first entry: have a history of at least two months of simultaneous DI and SSI beneficiary status during the 72-month time frame. 7 person-year observations were dropped due to missing values. The dependent variable in the cumulative probit takes on the following values: (1) zero; (2) greater than zero and less than SGA; (3) SGA to less than $2 * F B R+\$ 85$; (4) $2 * F B R+\$ 85$ or above. 
Figure 1. Stylized Example of Financial Incentives in the SSI and DI Programs DI-only

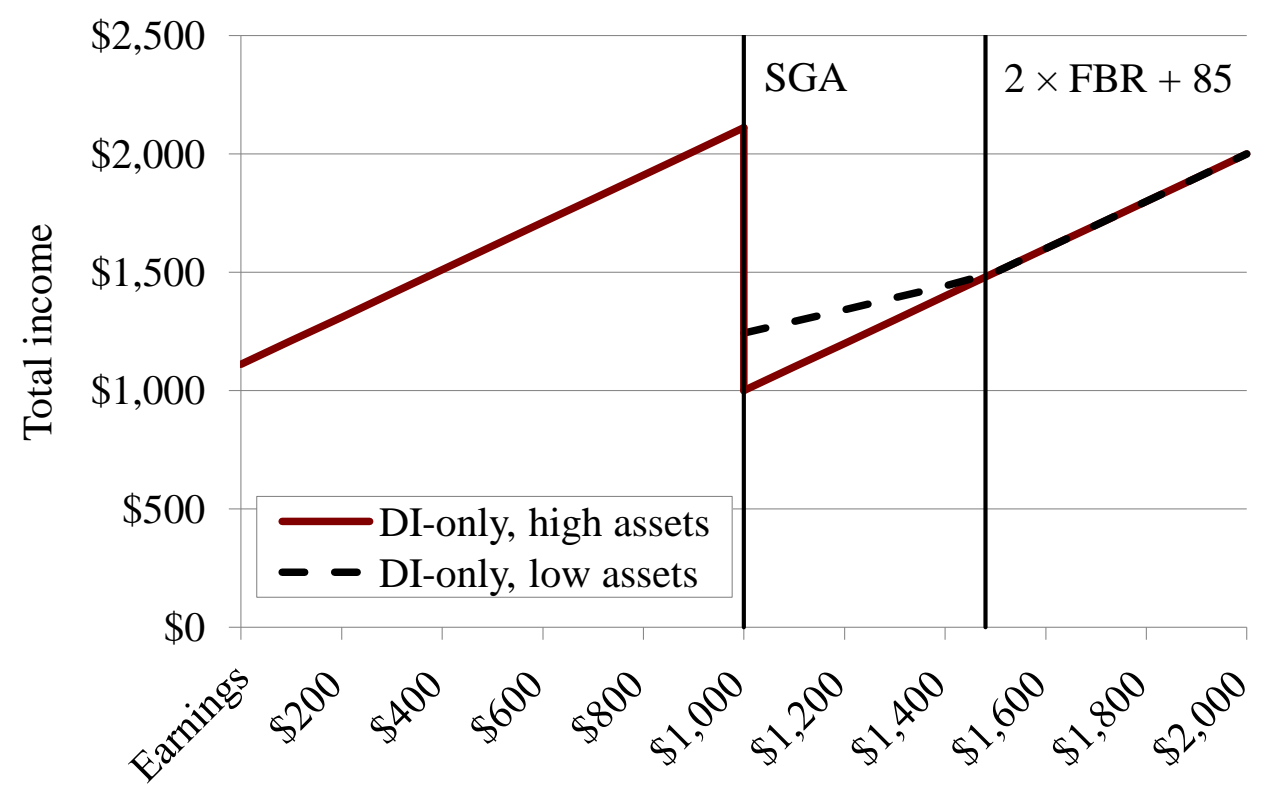

Earnings

Note: This is a stylized example for a single person who has no countable income outside of the SSI and DI programs. In the high-asset scenario, his assets disqualify him for SSI, in the low-asset scenario, the assets are low enough to qualify for SSI benefits. 
Figure 2. Stylized Example of Financial Incentives in the SSI and DI Programs DI-SSI Concurrent

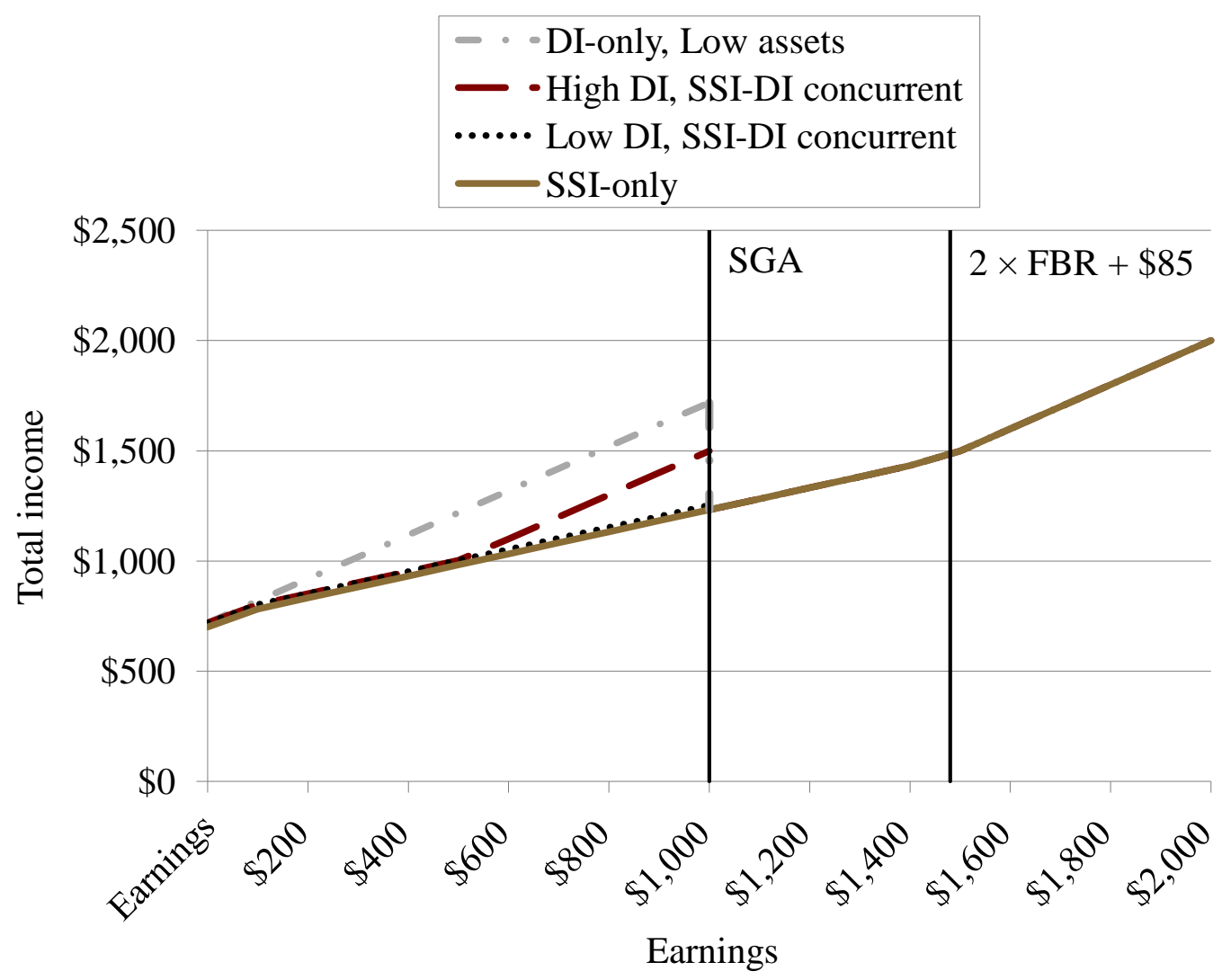

Note: This is a stylized example for a single person who passes the SSI asset test and has no countable income outside of the SSI and DI programs. 
Figure 3. Number of States with Strict Health Insurance Regulation

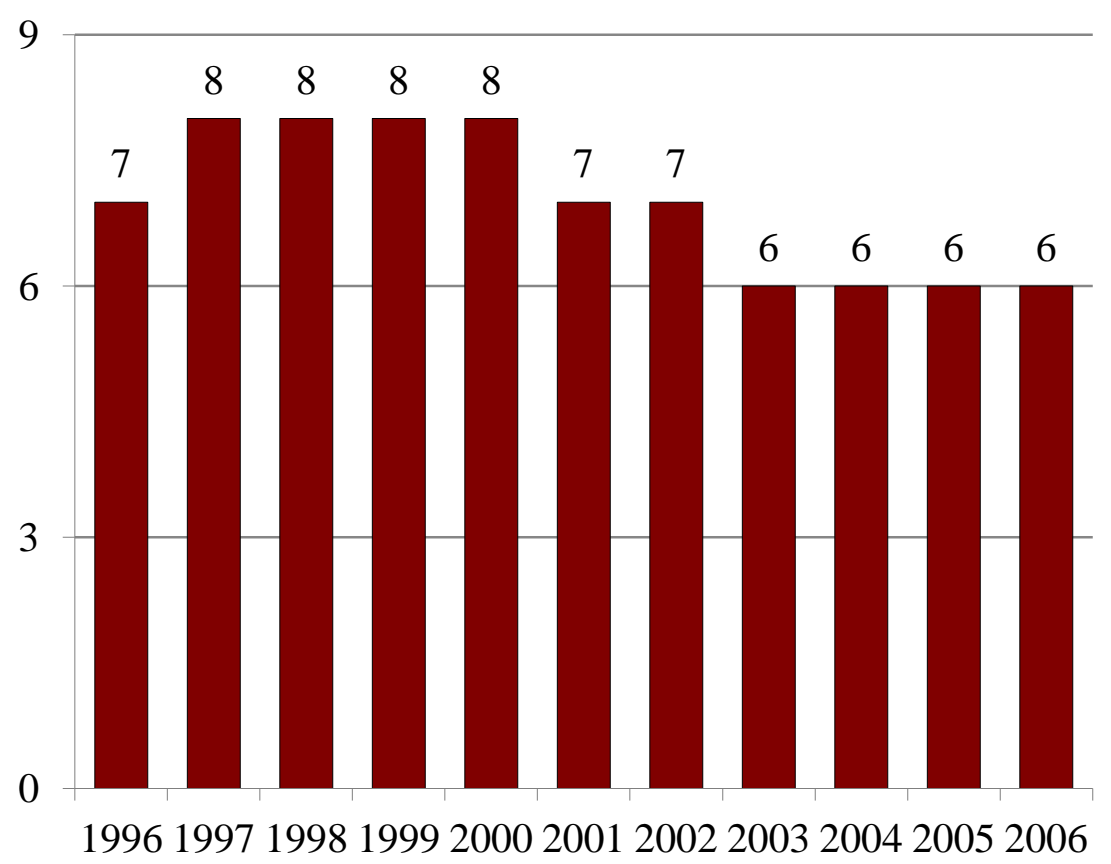

Figure 4. Number of States with Medicaid Buy-in Programs

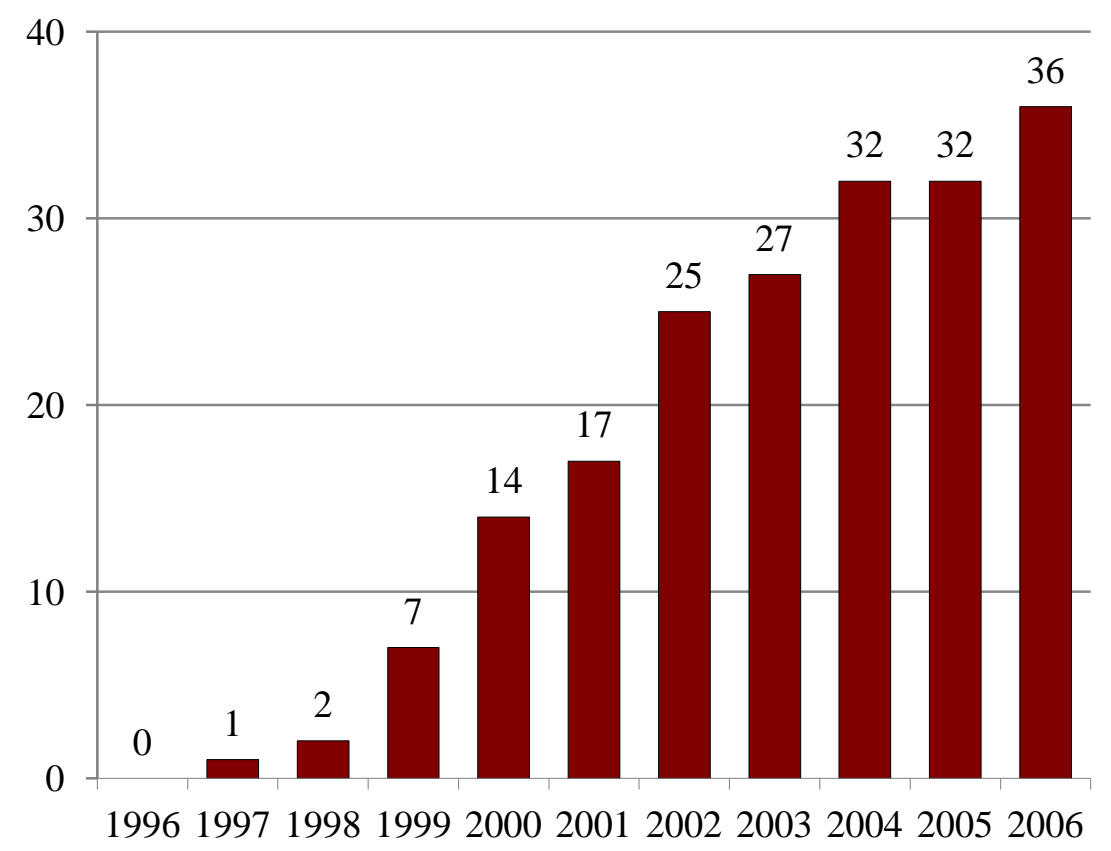


Figure 5. Number of States with Large Changes in Their Medicaid Generosity

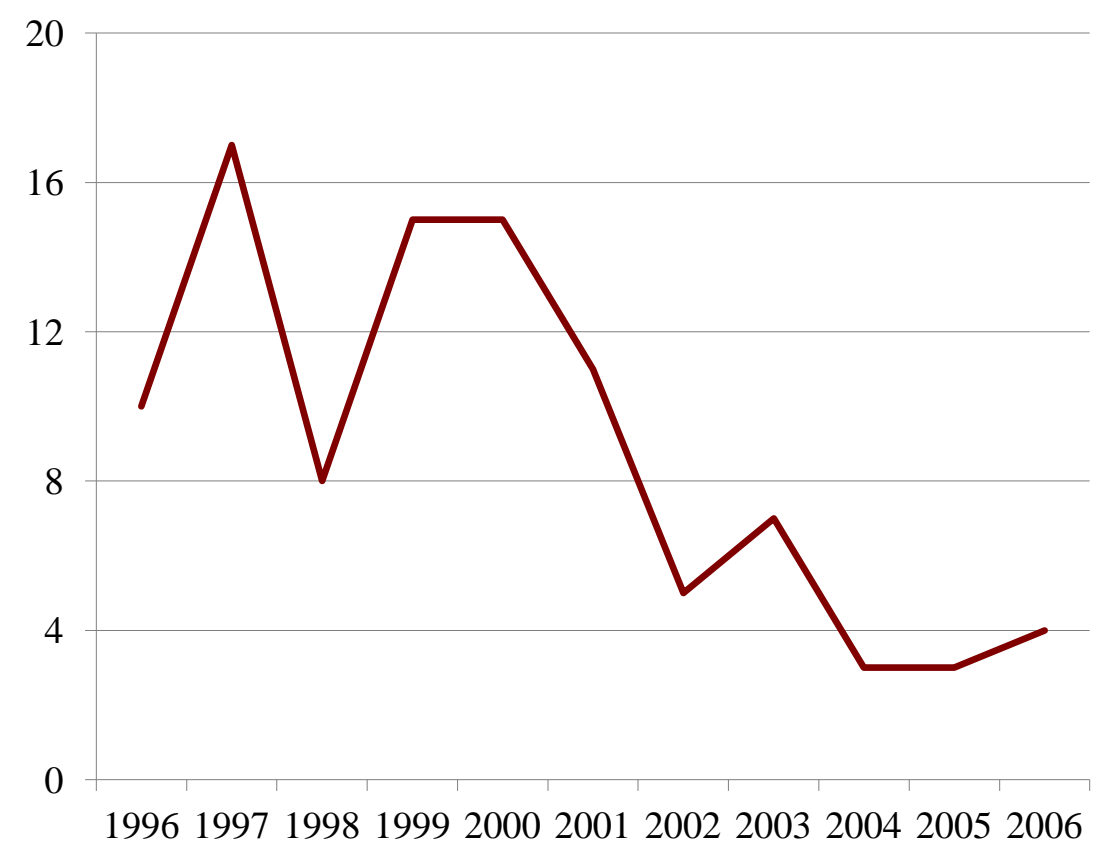


Appendix Table 1. Direct Effect of State Health Insurance Policies on Positive Earnings Among Disability Beneficiaries

Hypothesis 1

\begin{tabular}{|c|c|c|c|c|}
\hline & $\mathrm{ALL}^{1}$ & DI-only $^{2}$ & SSI-only $^{2}$ & Both DI and SSI ${ }^{2}$ \\
\hline \multicolumn{5}{|l|}{ State health insurance policy } \\
\hline \multirow[t]{3}{*}{ Strict regulation } & -0.018 & -0.036 & -0.011 & -0.047 \\
\hline & $(0.015)$ & $(0.024)$ & 0.024 & 0.039 \\
\hline & {$[-0.003]$} & {$[-0.004]$} & [- 0.002] & {$[-0.007]$} \\
\hline \multirow[t]{3}{*}{ Medicaid buy-in program } & $0.026 *$ & $0.022 *$ & $0.028 *$ & 0.014 \\
\hline & $(0.004)$ & $(0.006)$ & 0.006 & 0.009 \\
\hline & {$[0.004]$} & {$[0.002]$} & {$[0.005]$} & {$[0.002]$} \\
\hline \multirow[t]{3}{*}{ Medicaid generosity } & 0.001 & $-0.024 *$ & $0.031 *$ & 0.023 \\
\hline & $(0.007)$ & $(0.011)$ & 0.012 & 0.017 \\
\hline & {$[0.000]$} & {$[-0.003]$} & {$[0.005]$} & {$[0.004]$} \\
\hline \multicolumn{5}{|l|}{ Disability diagnoses } \\
\hline \multirow[t]{3}{*}{ Congenital } & $0.225 *$ & $0.438 *$ & $-0.262 *$ & $0.524 *$ \\
\hline & $(0.015)$ & $(0.029)$ & 0.021 & 0.032 \\
\hline & {$[0.034]$} & {$[0.062]$} & [- 0.043] & {$[0.078]$} \\
\hline \multirow[t]{3}{*}{ Endocrine } & $-0.032 *$ & $0.027 *$ & $-0.267 *$ & $0.116 *$ \\
\hline & $(0.006)$ & $(0.009)$ & 0.011 & 0.015 \\
\hline & {$[-0.004]$} & {$[0.003]$} & {$[-0.044]$} & {$[0.014]$} \\
\hline \multirow[t]{3}{*}{ Infection or parasitic } & $0.387 *$ & $0.576 *$ & $-0.064 *$ & $0.570 *$ \\
\hline & $(0.008)$ & $(0.011)$ & 0.014 & 0.018 \\
\hline & [ 0.062] & {$[0.088]$} & {$[-0.011]$} & {$[0.086]$} \\
\hline \multirow[t]{3}{*}{ Injury } & $0.049 *$ & $0.147 *$ & $-0.298 *$ & $0.135 *$ \\
\hline & $(0.006)$ & $(0.008)$ & 0.012 & 0.014 \\
\hline & [ 0.007] & [ 0.018$]$ & {$[-0.049]$} & [ 0.017$]$ \\
\hline \multirow[t]{3}{*}{ Intellectual disability } & $0.382 *$ & $0.851 *$ & $-0.218 *$ & $0.734 *$ \\
\hline & $(0.004)$ & $(0.007)$ & 0.007 & 0.009 \\
\hline & {$[0.061]$} & {$[0.148]$} & {$[-0.037]$} & [ 0.119] \\
\hline \multirow[t]{3}{*}{ Mental } & $0.165 *$ & $0.245 *$ & $-0.186 *$ & $0.425 *$ \\
\hline & $(0.003)$ & 0.004 & 0.006 & 0.008 \\
\hline & [ 0.024$]$ & {$[0.031]$} & {$[0.032]$} & {$[0.060]$} \\
\hline \multirow[t]{3}{*}{ Neoplasm } & $0.611 *$ & $0.573 *$ & $0.460 *$ & $0.674 *$ \\
\hline & $(0.007)$ & $(0.009)$ & 0.012 & 0.018 \\
\hline & [ 0.107] & [ 0.087] & [ 0.089] & {$[0.106]$} \\
\hline \multirow[t]{3}{*}{ Circulatory } & $0.095 *$ & $0.101 *$ & 0.017 & -0.003 \\
\hline & $(0.005)$ & $(0.006)$ & 0.009 & 0.014 \\
\hline & [ 0.014$]$ & {$[0.012]$} & {$[0.003]$} & {$[-0.000]$} \\
\hline \multirow[t]{2}{*}{ Digestive } & $0.141 *$ & $0.179 *$ & $-0.052 *$ & $0.149 *$ \\
\hline & $(0.009)$ & $(0.013)$ & 0.016 & 0.023 \\
\hline
\end{tabular}


Appendix Table 1. Direct Effect of State Health Insurance Policies on Positive Earnings Among Disability Beneficiaries (cont'd)

\begin{tabular}{|c|c|c|c|c|}
\hline & $\mathrm{ALL}^{1}$ & DI-only ${ }^{2}$ & SSI-only $^{2}$ & $\begin{array}{c}\text { Both DI and } \\
\text { SSI }^{2}\end{array}$ \\
\hline \multirow{3}{*}{ Genitourinary } & {$[0.021]$} & {$[0.022]$} & {$[-0.009]$} & [ 0.019] \\
\hline & $0.684 *$ & $0.967 *$ & $0.147 *$ & $0.765 *$ \\
\hline & $(0.008)$ & $(0.011)$ & 0.017 & 0.022 \\
\hline \multirow{3}{*}{ Nervous system } & [ 0.123$]$ & [ 0.177$]$ & [ 0.027$]$ & [ 0.125$]$ \\
\hline & $0.123 *$ & $0.192 *$ & $-0.243 *$ & $0.371 *$ \\
\hline & $(0.004)$ & $(0.006)$ & 0.008 & 0.010 \\
\hline \multirow{3}{*}{ Respiratory } & [ 0.018$]$ & [ 0.024$]$ & {$[-0.041]$} & [ 0.051$]$ \\
\hline & $0.061 *$ & $-0.068 *$ & $0.058 *$ & 0.019 \\
\hline & $(0.007)$ & $(0.010)$ & 0.012 & 0.020 \\
\hline \multirow{3}{*}{ Other } & [ 0.009$]$ & {$[-0.007]$} & [ 0.010$]$ & [ 0.002$]$ \\
\hline & $0.286 *$ & $0.269 *$ & 0.002 & $0.573 *$ \\
\hline & $(0.011)$ & $(0.018)$ & 0.017 & 0.025 \\
\hline \multirow{3}{*}{ Unknown } & [ 0.044$]$ & [ 0.035$]$ & [ 0.000$]$ & [ 0.087] \\
\hline & $0.437 *$ & $0.401 *$ & $0.180 *$ & $0.475 *$ \\
\hline & $(0.004)$ & 0.007 & 0.006 & 0.012 \\
\hline \multirow{4}{*}{ Presence of secondary diagnosis indicator } & {$[0.072]$} & {$[0.056]$} & [ 0.033$]$ & [ 0.069] \\
\hline & $-0.141 *$ & $-0.306 *$ & $0.045 *$ & $-0.085 *$ \\
\hline & $(0.002)$ & $(0.003)$ & 0.003 & 0.005 \\
\hline & {$[-0.040]$} & {$[-0.064]$} & {$[0.015]$} & {$[-0.026]$} \\
\hline \multicolumn{5}{|l|}{ Health insurance history } \\
\hline \multirow[t]{3}{*}{ Months on Medicaid } & $-0.072 *$ & $-0.029 *$ & $-0.078 *$ & $-0.062 *$ \\
\hline & $(0.000)$ & $(0.001)$ & 0.001 & 0.001 \\
\hline & {$[-0.010]$} & {$[-0.003]$} & {$[-0.013]$} & {$[-0.010]$} \\
\hline \multirow[t]{2}{*}{ Months on Medicaid last year } & $-0.042 *$ & $-0.020 *$ & $-0.029 *$ & $-0.024 *$ \\
\hline & $(0.000)$ & 0.001 & 0.001 & 0.001 \\
\hline \multirow{4}{*}{ Moderate Medicaid expenditures } & {$[-0.006]$} & {$[-0.002]$} & {$[-0.005]$} & {$[-0.004]$} \\
\hline & $-0.229 *$ & $-0.218 *$ & $-0.061 *$ & $-0.303 *$ \\
\hline & $(0.004)$ & $(0.008)$ & 0.006 & 0.010 \\
\hline & [- 0.038] & {$[-0.025]$} & [- 0.032] & [- 0.055] \\
\hline \multirow[t]{2}{*}{ Moderate Medicaid expenditures last year } & $-0.141 *$ & $-0.059 *$ & $-0.149 *$ & $-0.120 *$ \\
\hline & $(0.004)$ & $(0.008)$ & 0.006 & 0.010 \\
\hline \multirow{3}{*}{ High Medicaid expenditures } & {$[-0.024]$} & {$[-0.002]$} & {$[-0.031]$} & [- 0.023] \\
\hline & $-0.331 *$ & $-0.200 *$ & $-0.419 *$ & $-0.247 *$ \\
\hline & $(0.005)$ & $(0.011)$ & 0.008 & 0.012 \\
\hline \multirow{3}{*}{ High Medicaid expenditures last year } & {$[-0.053]$} & [-0.023] & [- 0.081] & {$[-0.046]$} \\
\hline & $-0.171 *$ & 0.017 & $-0.319 *$ & 0.001 \\
\hline & $(0.005)$ & $(0.011)$ & 0.008 & 0.012 \\
\hline
\end{tabular}


Appendix Table 1. Direct Effect of State Health Insurance Policies on Positive Earnings Among Disability Beneficiaries (cont'd)

\begin{tabular}{|c|c|c|c|c|}
\hline & $\mathrm{ALL}^{1}$ & DI-only ${ }^{2}$ & SSI-only $^{2}$ & $\begin{array}{c}\text { Both DI and } \\
\text { SSI }^{2}\end{array}$ \\
\hline \multirow{4}{*}{ Months on Medicare } & {$[-0.029]$} & {$[0.002]$} & {$[0.063]$} & {$[0.000]$} \\
\hline & $-0.127 *$ & $-0.136 *$ & $-0.042 *$ & $-0.102 *$ \\
\hline & $(0.001)$ & $(0.001)$ & 0.002 & 0.001 \\
\hline & {$[-0.018]$} & {$[-0.014]$} & {$[-0.007]$} & {$[-0.016]$} \\
\hline \multirow[t]{3}{*}{ Months on Medicare last year } & 0.009 & $-0.040 *$ & $0.011 *$ & -0.002 \\
\hline & $(0.001)$ & $(0.001)$ & 0.003 & 0.001 \\
\hline & {$[0.001]$} & {$[-0.004]$} & {$[0.002]$} & {$[-0.000]$} \\
\hline \multirow[t]{3}{*}{ Moderate Medicare expenditures } & $-0.120 *$ & $-0.137 *$ & $-0.061 *$ & $-0.062 *$ \\
\hline & $(0.004)$ & $(0.005)$ & 0.021 & 0.007 \\
\hline & {$[-0.021]$} & {$[-0.017]$} & {$[-0.013]$} & {$[-0.012]$} \\
\hline \multirow[t]{3}{*}{ Moderate Medicare expenditures last year } & $0.085 *$ & $0.045 *$ & $0.053 *$ & $0.114 *$ \\
\hline & $(0.004)$ & $(0.005)$ & 0.024 & 0.007 \\
\hline & {$[0.016]$} & {$[0.006]$} & {$[0.011]$} & {$[0.024]$} \\
\hline \multirow[t]{3}{*}{ High Medicare expenditures } & $-0.326 *$ & $-0.313 *$ & $-0.673 *$ & $-0.324 *$ \\
\hline & $(0.005)$ & $(0.006)$ & 0.031 & 0.010 \\
\hline & {$[-0.052]$} & {$[-0.035]$} & {$[-0.121]$} & {$[-0.059]$} \\
\hline \multirow[t]{3}{*}{ High Medicare expenditures last year } & $-0.117 *$ & $-0.128 *$ & $-0.611 *$ & $-0.175 *$ \\
\hline & $(0.006)$ & $(0.007)$ & 0.035 & 0.010 \\
\hline & {$[-0.016]$} & {$[-0.013]$} & {$[-0.089]$} & {$[-0.026]$} \\
\hline \multirow[t]{3}{*}{ Covered by both Medicaid and Medicare } & $0.811 *$ & $0.352 *$ & $0.684 *$ & $0.409 *$ \\
\hline & $(0.005)$ & $(0.009)$ & 0.021 & 0.010 \\
\hline & {$[0.136]$} & {$[0.042]$} & {$[0.133]$} & {$[0.059]$} \\
\hline \multirow[t]{3}{*}{ Covered by both Medicaid and Medicare last year } & $0.739 *$ & $0.395 *$ & $0.622 *$ & $0.321 *$ \\
\hline & $(0.005)$ & $(0.009)$ & 0.025 & 0.010 \\
\hline & {$[0.123]$} & {$[0.048]$} & {$[0.120]$} & {$[0.047]$} \\
\hline \multirow[t]{3}{*}{ Medicare is secondary payer } & -0.003 & $0.016 *$ & $0.287 *$ & $0.471 *$ \\
\hline & $(0.006)$ & $(0.006)$ & 0.045 & 0.016 \\
\hline & {$[-0.000]$} & {$[0.002]$} & [ 0.052$]$ & [ 0.086$]$ \\
\hline \multicolumn{5}{|l|}{ Demographics and earnings history } \\
\hline \multirow[t]{3}{*}{ Female } & $0.050 *$ & 0.096 * & $0.070 *$ & -0.003 \\
\hline & $(0.002)$ & $(0.003)$ & $(0.003)$ & $(0.004)$ \\
\hline & [ 0.007] & [ 0.010$]$ & [ 0.012$]$ & {$[-0.001]$} \\
\hline \multirow[t]{3}{*}{ Age 18-24 } & $2.252 *$ & $1.635 *$ & $3.174 *$ & $1.763 *$ \\
\hline & $(0.006)$ & $(0.014)$ & $(0.012)$ & $(0.016)$ \\
\hline & [ 0.414$]$ & [ 0.268$]$ & [ 0.474$]$ & {$[0.262]$} \\
\hline \multirow[t]{3}{*}{ Age 25-29 } & 1.965 * & $1.722 *$ & $2.819 *$ & $1.758 *$ \\
\hline & (0.006) & $(0.011)$ & $(0.012)$ & (0.015) \\
\hline & [ 0.325$]$ & [ 0.293] & [ 0.377$]$ & [ 0.261$]$ \\
\hline \multirow[t]{2}{*}{ Age 30-34 } & $1.646 *$ & 1.378 * & $2.469 *$ & $1.482 *$ \\
\hline & $(0.005)$ & (0.008) & $(0.012)$ & $(0.014)$ \\
\hline & {$[0.236]$} & [ 0.198$]$ & {$[0.290]$} & {$[0.190]$} \\
\hline \multirow[t]{3}{*}{ Age 35-39 } & $1.355 *$ & $1.078 *$ & $2.146 *$ & $1.269 *$ \\
\hline & (0.005) & $(0.007)$ & $(0.012)$ & (0.014) \\
\hline & [ 0.167] & [ 0.131] & [ 0.220$]$ & [ 0.144] \\
\hline
\end{tabular}


Appendix Table 1. Direct Effect of State Health Insurance Policies on Positive Earnings Among Disability Beneficiaries (cont'd)

\begin{tabular}{|c|c|c|c|c|}
\hline & $\mathrm{ALL}^{1}$ & DI-only ${ }^{2}$ & SSI-only $^{2}$ & $\begin{array}{c}\text { Both DI and } \\
\text { SSI }^{2}\end{array}$ \\
\hline \multirow[t]{3}{*}{ Age 45-49 } & $0.830 *$ & $0.585 *$ & $1.536 *$ & $0.804 *$ \\
\hline & $(0.005)$ & $(0.006)$ & $(0.012)$ & $(0.014)$ \\
\hline & {$[0.075]$} & {$[0.052]$} & {$[0.115]$} & {$[0.067]$} \\
\hline \multirow[t]{3}{*}{ Age $50-54$} & $0.538 *$ & $0.323 *$ & $1.211 *$ & $0.528 *$ \\
\hline & $(0.005)$ & $(0.006)$ & $(0.012)$ & $(0.014)$ \\
\hline & {$[0.040]$} & [ 0.024$]$ & [ 0.075$]$ & {$[0.036]$} \\
\hline \multirow[t]{3}{*}{ Age 55-61 } & $0.192 *$ & $0.065 *$ & $0.759 *$ & $0.233 *$ \\
\hline & $(0.005)$ & $(0.006)$ & $(0.012)$ & $(0.014)$ \\
\hline & [ 0.029] & {$[0.007]$} & {$[0.144]$} & [ 0.039] \\
\hline \multicolumn{5}{|c|}{$1-4$ years with zero earnings $6-10$ years prior to } \\
\hline \multirow[t]{2}{*}{ first-ever disability award } & $\begin{array}{l}-0.137 * \\
(0.003)\end{array}$ & $\begin{array}{l}-0.075 * \\
(0.004)\end{array}$ & $\begin{array}{l}-0.255 * \\
(0.004)\end{array}$ & $\begin{array}{l}-0.085 * \\
(0.006)\end{array}$ \\
\hline & {$[-0.020]$} & {$[-0.008]$} & {$[-0.045]$} & {$[-0.013]$} \\
\hline \multicolumn{5}{|c|}{$\begin{array}{l}5 \text { years with zero earnings } 6-10 \text { years prior to first- } \\
\text { ever disability award }\end{array}$} \\
\hline & $\begin{array}{l}-0.326 * \\
(0.003)\end{array}$ & $\begin{array}{l}-0.393 * \\
(0.007)\end{array}$ & $\begin{array}{l}-0.400 * \\
(0.004)\end{array}$ & $\begin{array}{l}0.036 * \\
(0.007)\end{array}$ \\
\hline & {$[-0.043]$} & {$[-0.035]$} & {$[-0.066]$} & {$[0.006]$} \\
\hline Average earnings 6-10 yea & & & & \\
\hline$(\$ 1,000 s)$ & 0.000 * & 0.000 * & 0.000 * & 0.000 \\
\hline & $(0.000)$ & $(0.000)$ & $(0.000)$ & $(0.000)$ \\
\hline & {$[0.000]$} & {$[0.000]$} & {$[0.000]$} & {$[0.000]$} \\
\hline \multicolumn{5}{|l|}{ Disability program information ${ }^{2}$} \\
\hline \multirow[t]{3}{*}{ Both DI and SSI } & $0.303 *$ & -- & -- & -- \\
\hline & $(0.004)$ & -- & -- & -- \\
\hline & {$[0.042]$} & -- & -- & -- \\
\hline \multirow[t]{3}{*}{ Only DI } & $0.274 *$ & -- & -- & -- \\
\hline & $(0.004)$ & -- & -- & -- \\
\hline & [ 0.038$]$ & -- & -- & -- \\
\hline \multicolumn{5}{|c|}{ Number of months since first-ever disability award: } \\
\hline \multirow[t]{2}{*}{$1-12$ months $^{4}$} & $\begin{array}{l}-0.629 * \\
(0.006)\end{array}$ & $\begin{array}{l}-1.518 * \\
(0.010)\end{array}$ & $\begin{array}{l}-0.294 * \\
(0.009)\end{array}$ & $\begin{array}{l}-0.864 * \\
(0.017)\end{array}$ \\
\hline & {$[-0.073]$} & {$[-0.116]$} & {$[-0.048]$} & {$[-0.093]$} \\
\hline \multicolumn{5}{|c|}{ Number of months since first-ever disability award: } \\
\hline \multirow[t]{2}{*}{$13-24$ months $^{4}$} & $\begin{array}{l}-0.459 * \\
(0.006)\end{array}$ & $-1.221 *$ & $\begin{array}{l}-0.147 * \\
(0.010)\end{array}$ & $\begin{array}{l}-0.768 * \\
(0.015)\end{array}$ \\
\hline & {$[-0.057]$} & {$[-0.104]$} & {$[-0.025]$} & {$[-0.086]$} \\
\hline \multicolumn{5}{|c|}{ Number of months since first-ever disability award: } \\
\hline \multirow[t]{2}{*}{$25-36$ months $^{4}$} & $\begin{array}{l}-0.080 * \\
(0.006)\end{array}$ & $\begin{array}{l}-0.297 * \\
(0.009)\end{array}$ & $\begin{array}{l}-0.080 * \\
(0.010)\end{array}$ & $\begin{array}{l}-0.227 * \\
(0.016)\end{array}$ \\
\hline & {$[-0.012]$} & {$[-0.036]$} & {$[0.014]$} & {$[-0.032]$} \\
\hline
\end{tabular}


Appendix Table 1. Direct Effect of State Health Insurance Policies on Positive Earnings Among Disability Beneficiaries (cont'd)

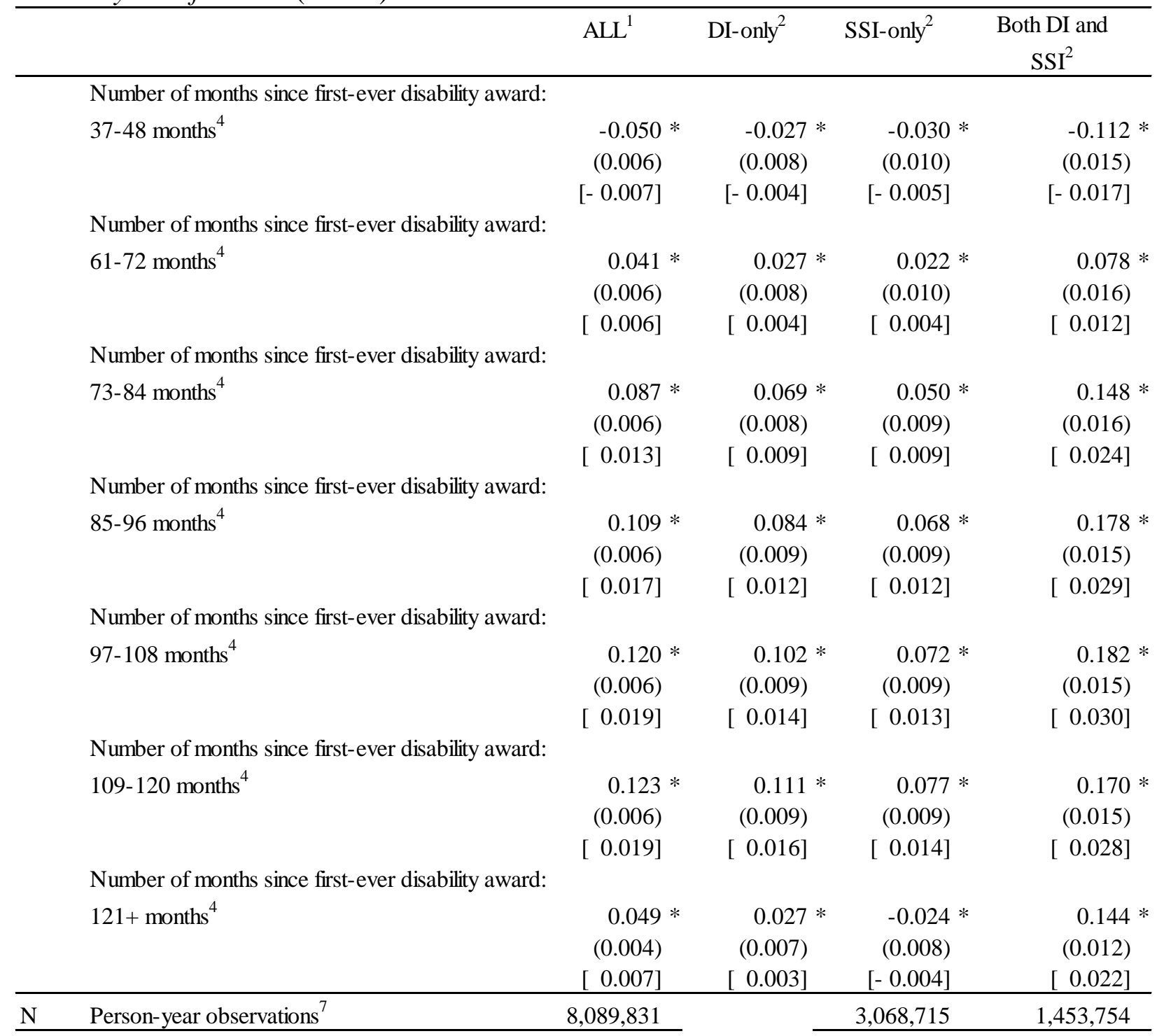

Note: All regressions also include state and year fixed-effects. The table presents the coefficients, standard errors (in parentheses), and marginal effects (in brackets) from a probit model. Coefficients estimated to be statistically significantly different from zero at the 0.95 level of confidence are indicated by "*". Note that standard error estimates assume single random sampling and therefore include some downward bias.

110 percent sample of current or former DI and/or SSI disability beneficiaries aged 18-64 and alive during 2000-2006 reference year based on individual records from SSA and CMS administrative data systems.

2 Classification is based on DI-only or SSI-only benefit-receipt between first-ever disability award and the reference year with a residual category of beneficiaries with at least one month in DI, and at least one month in SSI benefit receipt status during the given time-period.

5 Months on Medicaid or Medicaid variables refer to the reference person-year observation. "Last year" refers to year immediately prior to reference year. Expenditure data are limited to program expenditures by the Medicaid and/or Medicaid programs based on CMS administrative records. For both programs expenditures were classified as follows: (a) no expenditure during year; (b) "moderate" expenditure defined as \$1-\$6,000; (c) "high" expenditure defined as \$6,001 or over. In all of the regressions "no expenditure" is the reference category.

${ }^{6}$ Number of calendar months elapsing between first-ever disability award and January of the reference year. May include months in non-beneficiary status, and therefore can be interpreted as upper-bound estimate of duration of disability benefit receipt (DI and/or SSI) during given time period.

${ }^{7}$ Person-year observations are slightly lower than those reported in Table 1 descriptive analysis as a result of missing values resulting in exclusion of person-year observations from the model estimating the equations. 


\section{RECENT WORKING PAPERS FROM THE CENTER FOR RETIREMENT RESEARCH AT BOSTON COLLEGE}

How Will Older Workers Who Lose Their Jobs During the Great Recession Fare in the Long-Run?

Matthew S. Rutledge, Natalia Orlova, and Anthony Webb, March 2013

Can Long-Term Care Insurance Partnership Programs Increase Coverage and Reduce Medicaid Costs?

Wei Sun and Anthony Webb, March 2013

SSI for Disabled Immigrants: Why Do Ethnic Networks Matter?

Delia Furtado and Nikolaos Theodoropoulos, February 2013

The Use of VA Disability Benefits and Social Security Disability Insurance Among Veterans

Janet M. Wilmoth, Andrew S. London, and Colleen M. Heflin, February 2013

How Does the Composition of Disability Insurance Applicants Change Across Business Cycles?

Norma B. Coe and Matthew S. Rutledge, February 2013

The Economic Implications of the Department of Labor's 2010 Proposals for BrokerDealers

Alicia H. Munnell, Anthony Webb, and Francis M. Vitagliano, January 2013

What Is the Long-Term Impact of Zebley on Adult and Child Outcomes?

Norma B. Coe and Matthew S. Rutledge, January 2013

Sticky Ages: Why Is Age 65 Still a Retirement Peak?

Norma B. Coe, Mashfiqur Khan, and Matthew S. Rutledge, January 2013

Rethinking Optimal Wealth Accumulation and Decumulation Strategies in the Wake of the Financial Crisis

Richard W. Kopcke, Anthony Webb, and Josh Hurwitz, January 2013

Employee Mobility and Employer-Provided Retirement Plans

Gopi Shah Goda, Damon Jones, and Colleen Flaherty Manchester, November 2012

Changing Sources of Income Among the Aged Population

Barry P. Bosworth and Kathleen Burke, November 2012

All working papers are available on the Center for Retirement Research website

(http://crr.bc.edu) and can be requested by e-mail (crr@bc.edu) or phone (617-552-1762). 